\title{
A dynamic material flow analysis of lithium-ion battery metals for electric vehicles and grid storage in the UK: assessing the impact of shared mobility and end-of-life strategies.
}

\author{
Mashael Kamran ${ }^{1,2}$, Marco Raugei ${ }^{1,2} *$, and Allan Hutchinson ${ }^{1,2}$ \\ ${ }^{1}$ School of Engineering, Computing and Mathematics, Oxford Brookes University, UK \\ ${ }^{2}$ The Faraday Institution, UK \\ * Corresponding author: marco.raugei@brookes.ac.uk
}

\begin{abstract}
Limiting human-induced climate change represents a critical challenge for the future, and due to their disproportionate contribution to the problem, the energy and transport sectors are attracting the most attention in terms of emission reduction roadmaps and targets. Energy storage, particularly electrochemical storage, is poised to be a cornerstone in allowing those sectors to become more sustainable. This study presents the results of an integrated dynamic material flow analysis of the cumulative demand for lithiumion battery metals ( $\mathrm{Li}, \mathrm{Co}, \mathrm{Ni}$ and $\mathrm{Mn}$ ) by the light duty vehicle and electricity generation sectors in the UK over the next three decades. Results have shown that recycling of end-of-life electric vehicle battery packs is very effective in "closing the loop", and would enable driving the demand for all four metals back down to present levels by 2050, despite having achieved by then a complete shift to $100 \%$ electric vehicles. Additionally, repurposing end-of-life vehicle batteries for grid storage (with over $50 \mathrm{GWh}$ of grid storage capacity expected to be in place by 2050 ) has been found to enable reducing purpose-built grid storage batteries to zero. Finally, an additional scenario analysis has indicated that a widespread behavioural shift from conventional vehicle ownership to shared mobility could even drive the demand for virgin battery metals into negative territory by 2040 .
\end{abstract}

\section{Keywords:}

Lithium-ion batteries; electric vehicles; shared mobility; energy storage; recycling; material flow analysis.

\section{Introduction}

The relentless burning of fossil fuels to power modern societies since the industrial revolution has led to an unprecedented rapid increase in carbon dioxide $\left(\mathrm{CO}_{2}\right)$ concentration in the atmosphere from 280ppm (parts per million) to over 400ppm (Ritchie and Roser, 2020). The 2015 Paris agreement, signed by 195 countries, points to the need for drastic measures to limit global warming to $+2^{\circ} \mathrm{C}$ relative to pre-industrial levels and thus reduce the risk of irreversible climate consequences. Moving away from fossil fuels as principal sources of energy across all sectors is central to all such measures. Specifically, the energy and transport sectors are jointly responsible for approximately two thirds of total greenhouse gas emissions globally (WRI, 2020), and over $50 \%$ thereof in the UK (UK government, 2020). 
To address this pressing issue, National Grid Electricity System Operator, the UK's largest utility company, is investigating a range of "Future Energy Scenarios (FES)" (National Grid, 2020) characterised by reduced dependence on fossil fuels for the electricity and heat sectors in Great Britain ${ }^{1}$; these scenarios are updated each year. The most ambitious scenario in the 2019 version of National Grid's FES report was named "Two degrees" (in a clear reference to the Paris agreement), and it was the object of a thorough life cycle assessment (LCA) by the same authors (Raugei et al., 2020); its findings indicated the potential for over $75 \%$ reductions in non-biogenic carbon emissions from electricity production by 2050, compared to the present. In 2020, National Grid then renamed the scenarios, and made even more aggressive predictions in what is now referred to as the "Leading the way" scenario.

At the same time, the UK government has introduced a mandatory target to eventually end all sales of conventional internal combustion engine light-duty vehicles (LDVs). Discussions are now under way to shorten the timeline for such target, which was originally set for 2040 but is currently 2035, and which is now poised to be brought forward to 2030 (The Guardian, 2020).

The scientific literature is in broad agreement in identifying ample scope for solid environmental benefits of electric vehicles (EVs), when compared with conventional internal combustion engine vehicles (ICEVs). For instance, Faria et al. (2013) found that, depending on the grid supply mix of the country where they are driven, greenhouse gas (GHG) emissions by compact EVs may be reduced by as much as $60 \%$ with respect to conventional ICEVs of the same size segment. Broadly similar emission reduction results were also arrived at in two very recent independent life-cycle studies focusing on EV vs. ICEV GHG emissions respectively in Turkey (Ozdemir et al., 2020) and Lithuania (Petrauskienè et al., 2020). A paper by Hoekstra (2019) pointed out the critical roles of several parameters and assumptions to arrive at accurate estimations of the emission reduction potential afforded by replacing ICEVs with EVs, and concluded that, for a typical D-segment ${ }^{2}$ car in Europe, GHG emissions would drop by more than $60 \%$ over the full life cycle of the vehicle. Raugei et al. (2018) found that, already under current conditions, the overall life-cycle demand for non-renewable primary energy of a compact EV in the UK is lower by approximately $34 \%$ with respect to that of an otherwise similar ICEV, and that such reduction may be expected to improve further under most future grid mix scenarios.

However, despite the growing body of scientific literature looking into the environmental performance of present and future electricity grid mixes, and of electric vs. conventional vehicles, a pressing need remains for overarching, fully integrated consequential environmental analyses of the complex landscape of scenarios that may soon unfold as a result of the intricate interplay between the co-evolving energy and transport sectors. Specifically, lithium-ion batteries (LIBs) are a cornerstone energy storage technology in order to enable both the growth of electrical mobility and the large-scale deployment of renewable technologies in the electricity grid. As a result, the growing demand for LIB metals is expected to feature prominently as a shared challenge for the future (US DoE, 2011; BGS, 2020), as illustrated schematically by the influence diagram in Figure 1.

\footnotetext{
${ }^{1}$ National Grid does not provide electricity to Northern Ireland, which instead is served by three interconnectors with the Republic of Ireland. Consequently, while the FES are based on targets set at the national (UK) level, all the data contained therein are actually for Great Britain (GB) only, i.e., excluding Northern Ireland. For the sake of clarity and simplicity, however, in this paper the distinction between GB and UK is dropped in favour of a unified reference to "UK" throughout.

${ }^{2}$ The D-segment is the third largest of the European segments for passenger cars, and is described as "large cars". It is equivalent to the Euro NCAP "large family car" size class, and the present-day definition of the mid-size car category used in North America.
} 


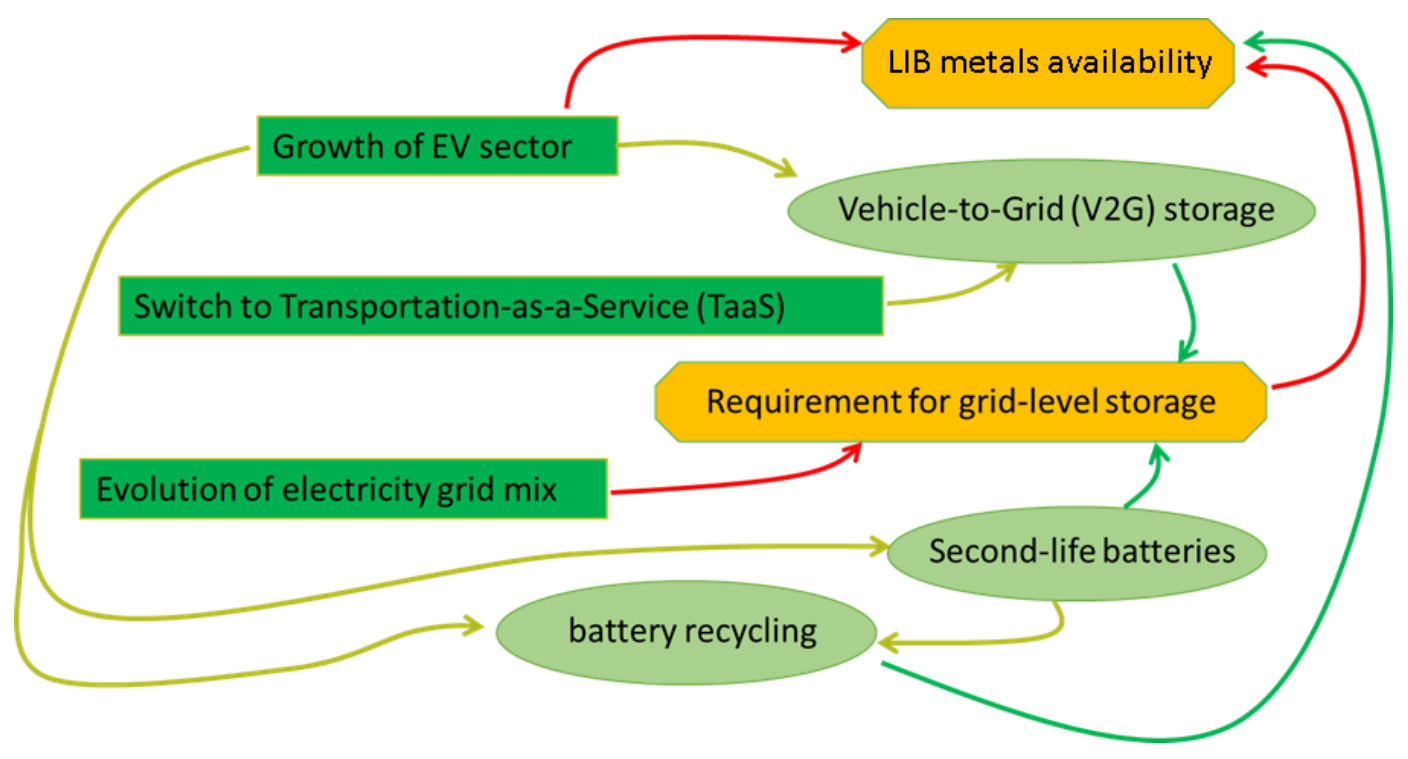

Figure 1. Influence diagram showing three on-going transformative transitions (decision nodes = dark green rectangles), the associated challenges for the future ("value" nodes = orange octagons), and the possible technological solutions (uncertainty nodes = light green ovals). Light green arrows indicate direct dependence; dark green arrows indicate a probabilistically conditioned reduction in severity for the challenge they point to; red arrows indicate a probabilistically conditioned increase in severity.

The current annual Li production rate is clearly insufficient to sustain a projected exponential growth in demand for EVs. There is still considerable uncertainty on the reserves of Li resources that may be ultimately economically recoverable, and on the rate at which production may be ramped up. This has led to open debate in the scientific literature on whether, and the time frame within which, Li availability is likely to start representing a serious limit to the widespread adoption of EVs (Grosjean et al., 2012; Speirs et al., 2014; Narins, 2017; Alves Dias et al., 2018; Greim et al., 2020). The issue is further compounded by possible future geopolitical concerns stemming from the fact that a significant share of the commercially exploitable $\mathrm{Li}$ reserves are localised within the confines of relatively restricted geographical areas, among which is the socalled 'white gold triangle' in South America (USGS, 2020a; Choubey et al., 2016; Choubey et al., 2017). Cobalt is intrinsically scarcer, and its continued future availability on the scale required for an exponentially growing production of LIBs using the currently leading chemistries for EV applications (i.e., NMC and NCA) is doubtful. Also, Co is a sensitive resource because it is mainly extracted from deposits found in the Democratic Republic of Congo (> 60\% of total world production (USGS, 2020b)), and Co mining attracts significant concerns because of the associated ecological toxicity.

Simultaneously, the evolution of the electricity grid mixes, gradually shifting away from the use of fossil fuels towards an increasing reliance on renewable, but inherently intermittent and hence non-dispatchable, energy sources (among which specifically solar and wind), points to the associated future challenge of having to provide at least some degree of grid-level energy storage (Lindley, 2010). One well-established technology to address this with comparatively low additional demand for primary energy and environmental impact per unit of energy stored is pumped hydro storage (PHS), whereby the excess electricity generated during times of peak renewable energy availability (e.g., solar at midday) is used to pump water from a suitable lower- 
altitude reservoir into a higher-altitude one. The water thus stored can be used later for the generation of hydroelectricity during times of high demand but low solar and wind availability. However, the viability of PHS is ultimately subject to stringent orographic constraints, and does not represent a universal solution to the intermittency problem. Other technologies such as compressed air energy storage (CAES), supercapacitors and magnetically levitated flywheels have been proposed, but each suffers from specific technical limitations that so far prevent them from representing likely solutions on a large scale. LIBs, instead, are a comparatively mature and reliable technology that can, in principle at least, be easily scaled up to meet the requirements posed by grid balancing and buffering. However, the associated requirements for raw minerals, and specifically Li, could become a hindrance to the widespread adoption of this technology for grid-level storage, too - especially if such evolution of the grid is indeed paralleled by an exponential growth in demand for the same metals for the EV sector, as discussed above.

A further transport-related transition is often discussed, from a conventional model largely based on private vehicle ownership to one in which the accent is shifted to the provision of transportation services (measured in person-kilometres and tonne-kilometres), wherein vehicles are shared among multiple users. Such a transition has the potential to make much more intensive (and hence efficient) use of the individual vehicles, and thereby indirectly reduce the cumulative demand for primary resources, among which are the batteryspecific metals discussed above. Additionally, a more widespread adoption of transportation-as-a-service (TaaS) would also make it more practical, from a logistics point of view, to implement vehicle-to-grid (V2G) energy storage schemes, whereby the LIBs in the EVs could be used to provide distributed buffer capacity to the electric grid while the vehicles are parked at corporate-controlled parking lots. Such V2G storage has been projected to represent a potentially critical contribution to the overall requirement for grid-level energy storage, and by reducing the demand for purpose-built LIB stacks, it could also indirectly reduce the severity of the challenge posed by future Li availability constraints (Sovacool and Hirsch, 2009; Hein et al., 2012).

Finally, a widespread adoption of EVs, both as privately owned cars and as TaaS vehicles, would quickly lead to a corresponding availability of decommissioned battery packs. This abundance of decommissioned EV LIBs could be exploited in two ways. Firstly, the decommissioned LIB packs could be repurposed for a 'second life' in stationary grid storage applications Abdel-Monem et al., 2017). This would contribute to reducing the severity of the challenge posed by the increasing demand for raw materials for purpose-built LIB stacks. Secondly, the availability of a critical mass of decommissioned LIBs (both directly out of EVs after their 'first life', and after a possible 'second life' as discussed above) may be expected to reduce, and even potentially eliminate, any lingering economic barriers to the widespread adoption of LIB recycling schemes, and thereby enable a large throughput of recovered metals (among which critically $L i$ and $\mathrm{Co}$ ) to actively reduce the demand for the corresponding virgin raw resources (Dewulf et al., 2010; Bálint et al., 2015; Ziemann et al., 2018; Mayyas et al., 2019; Baars et al., 2020).

In view of all of the above, and also in response to an explicit call for a Special Issue of this journal (Rajaeifar et al., 2020), this paper aims to contribute to laying the foundations for a future consequential life-cycle assessment of the co-evolution of the transport and energy sectors in the UK, by illustrating and discussing the results of a dynamic mass flow analysis of all the key lithium-ion battery metals: Li, Co, Mn and Ni. The key strength of this analysis lies in its relying on a fully integrated and internally consistent modelling approach that minimizes the number of independent variables and assumptions, and allows a quantitative estimation of the overall net demand for these metals via primary supply chains (i.e., from virgin resources). 


\section{Materials and Methods}

This section is structured into four separate but interdependent sub-sections, which illustrate the data sources, assumptions and calculation approaches used in this study to model: (1) the UK vehicle fleet; (2) the technical evolution of LIBs used in the EV sector; (3) LIB solutions to satisfy the future expected demand for grid-level energy storage (including considerations of V2G and second-life EV battery applications); and (4) LIB recycling. For full transparency, all detailed model equations are also reported in the Supplementary Information.

The four sub-models mentioned above are then combined to allow a complete mass flow analysis of the four key LIB metals Li, Co, Mn and $\mathrm{Ni}$ (see flow diagram in Figure 2), which is carried out three times to investigate three main alternative scenarios, namely:

(I) "worst case" scenario: TaaS achieves no penetration in the LDV fleet, and EoL EV LIBs are not collected to be re-used in second-life grid storage applications or recycled;

(II) "baseline" scenario: TaaS achieves no penetration in the LDV fleet, but widely available and steadily increasing EoL EV LIB collection rates and subsequent second-life and recycling;

(III) "TaaS" scenario: same as (II) but assuming a high penetration of TaaS.

For improved clarity, the key assumptions for the three analysed scenarios are summarised in Table 1, too.

\begin{tabular}{|lccc|}
\hline Scenario & “worst case" & "baseline" & "TaaS" \\
\hline $\begin{array}{l}\text { TaaS penetration } \\
\text { (\% of new LDV registrations) }\end{array}$ & $0 \%$ & $0 \%$ & $0 \%(2020)$ \\
\hline EoL EV LIB collection rate & $0 \%$ & $80 \%(2020)$ & $80 \%(2050)$ \\
& & $>99 \%(2050)$ & $>99 \%(2050)$ \\
\hline
\end{tabular}

Table 1. The three analysed scenarios and associated assumptions on TaaS penetration and end-of-life EV LIB collection. 


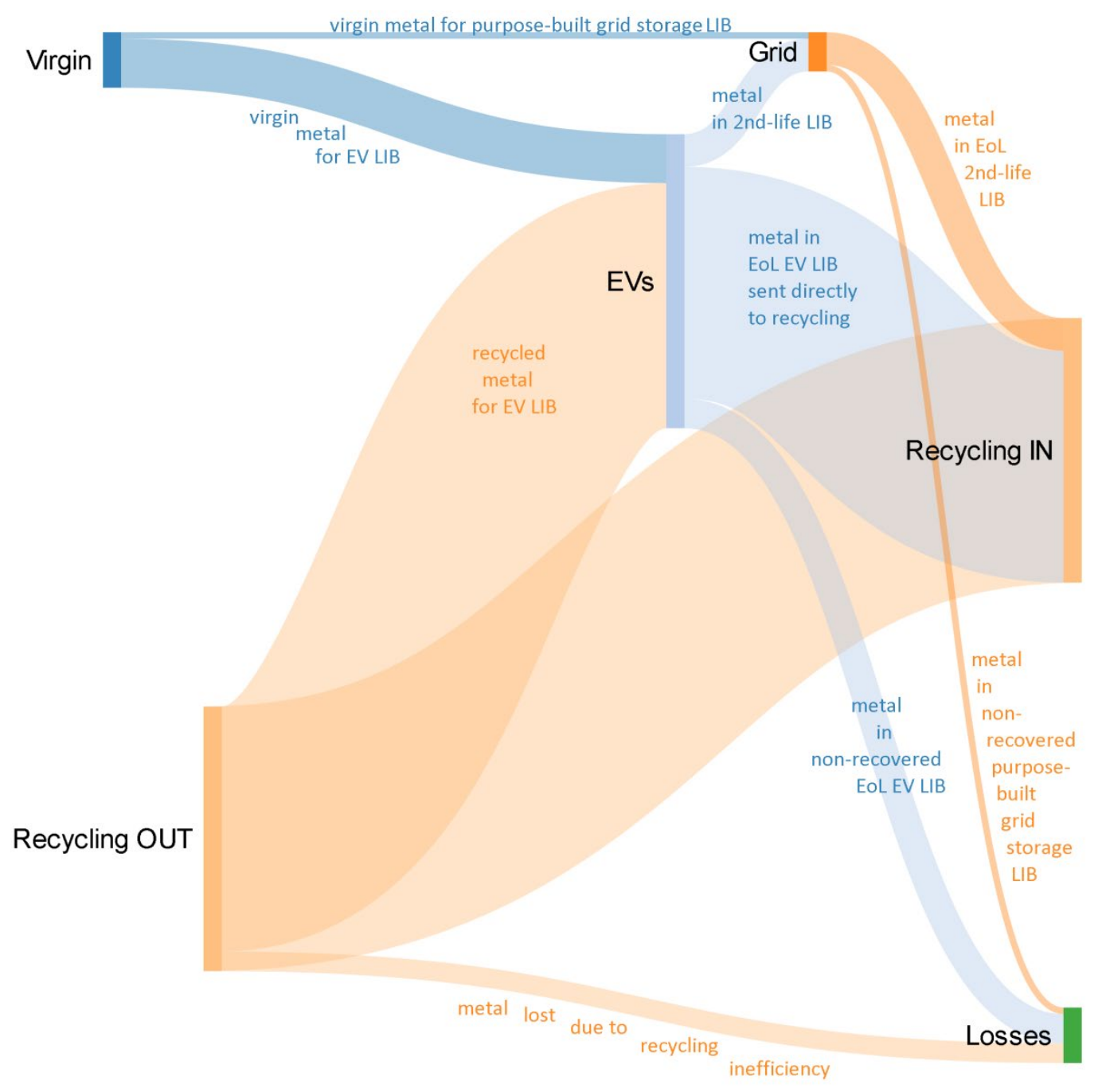

Figure 2. Generalised mass flow diagram for LIB metals ( $\mathrm{Li}, \mathrm{Co}, \mathrm{Mn}$ and $\mathrm{Ni}$ ) in the coupled light duty vehicle and electricity generation sectors. In the specific cases of $\mathrm{Co}$ and Ni, the flows from "Virgin" to "Grid" and from "Grid" to "Losses" are zero, since all purpose-built LIB storage for the grid is assumed to be LMO.

\subsection{Vehicle fleet}

The vehicle fleet model tracks the evolution of the light duty vehicle (LDV) fleet on UK roads. The UK transport system is undergoing transitions to achieve improved air quality, to meet the climate targets and to reduce congestion. As already mentioned, the government is planning to bring forward the ban of all diesel and petrol cars and vans sales, from 2040 to 2030, with the aim of having a fleet composed of virtually all zero emission motor vehicles by 2050 (Ambrose, 2020). The types of vehicles considered in this study are 4-wheeled cars and small vans. The study focuses on the transition from ICEVs towards EVs powered by LIBs, as these are considered to be the dominating technology for ultra-low emission vehicles in the LDV sector (DfT, 2018a). A second major transition in the vehicle fleet is the potential uptake of TaaS. The purpose of TaaS is to provide a shared and flexible mobility which attempts to minimize the private use of light duty vehicles, hence enabling a shift away from private vehicle ownership and potentially reducing the number of vehicles on the roads (Foresight, 2019; MaaS Alliance). Some of the types of LDVs that can be operated 
under TaaS are car-sharing schemes and ride-sharing schemes. Fleet operators of such schemes are among the early adopters of EVs, and so the rise of shared mobility vehicles is anticipated to be electric (Möller, T., 2019). Some of the adopters of TaaS schemes in the UK are the E-car club in London (E-Car Club), a co-car sharing club in Exeter (CoMoUK, 2020) and a proposed E-mobility hub project to start in 2021 in Nottingham and Derby to facilitate different EV sharing schemes (B. Kubitz, 2020). This paper refers to vehicles operating under private ownership as "private vehicles" and vehicles operating under shared mobility schemes as "TaaS vehicles".

In this study, the "worst case" and "baseline" scenarios assume zero penetration of TaaS, and the "TaaS" scenario assumes a high penetration of TaaS (up to $45 \%$ of all new vehicle registrations in 2050). Although in reality TaaS vehicles already represent a very small percentage in the current LDV fleet, the choice was made to settle on two such clearly defined scenarios in order to explore the clear impacts associated with the uptake of TaaS vehicles, all of which are assumed to be electric. Also, in light of the recent discussions on the planned ban of petrol and diesel LDV sales, all scenarios are set for a linear progression in the sales of new EVs, to reach $100 \%$ in 2030.

Table 2 shows the basic parameters of the vehicle fleet model. Total vehicles on the roads are taken as the combination of TaaS and private vehicles, the latter comprising of ICEVs and EVs. Average ICEVs in the UK have a lifetime millage of around 190,000 km, which is a weighted average for diesel and petrol vehicles (Ricardo-AEA, 2015). EVs have fewer powertrain components and moving parts as compared to ICEVs, leading to reduced wear and tear, and hence potentially extended vehicle lifetime mileage (Arbib \& Turner, 2017). However, this is less likely to be the case in practice, as the service costs, including specifically battery replacement, may make purchasing a new EV a more attractive option, even more so when considering that the EV sector is still young and undergoing rapid evolution. Hence, it is assumed that EVs would have the same lifetime mileage as ICEVs.

The total annual distance travelled (DT) by all LDVs on UK roads has been growing at a moderate rate, with slight fluctuations and a clear change in rate of increase at around the year 1990, as illustrated in Figure 3 (DfT, 2018b). Such annual distance travelled, also referred to as vehicle miles travelled (VMT), is calculated each year by the Department for Transport (DfT, 2020) as the product of the estimated annual average daily flow (AADF) multiplied by the road length, where AADF is the average of the number of vehicles per day passing a point in the road network (DfT, 2020). Department for Transport have also published a number of future forecasts of road traffic, congestion and emissions up to 2050 (DFT, 2018c); among these, the "Reference" scenario projects a 34\% increase in total annual distance travelled by cars from 2015 to 2050 in England and Wales. That same relative \% increase is then assumed here to apply to all LDVs in the UK as a whole, leading to a projected DT $=532$ billion $\mathrm{km}$ in 2050. By way of sensitivity analysis, a second set of calculation results for LIB metals mass flows are also reported separately in the Supplementary Information, under the alternative assumption that DT will remain constant from 2020 all the way to 2050. This is intended to represent a lower-bound estimate for the future evolution of DT, which could reflect a permanent behavioural shift towards more home-based working and less commuting, in line with the trend observed in the year 2020 under COVID-19 pandemic conditions. 


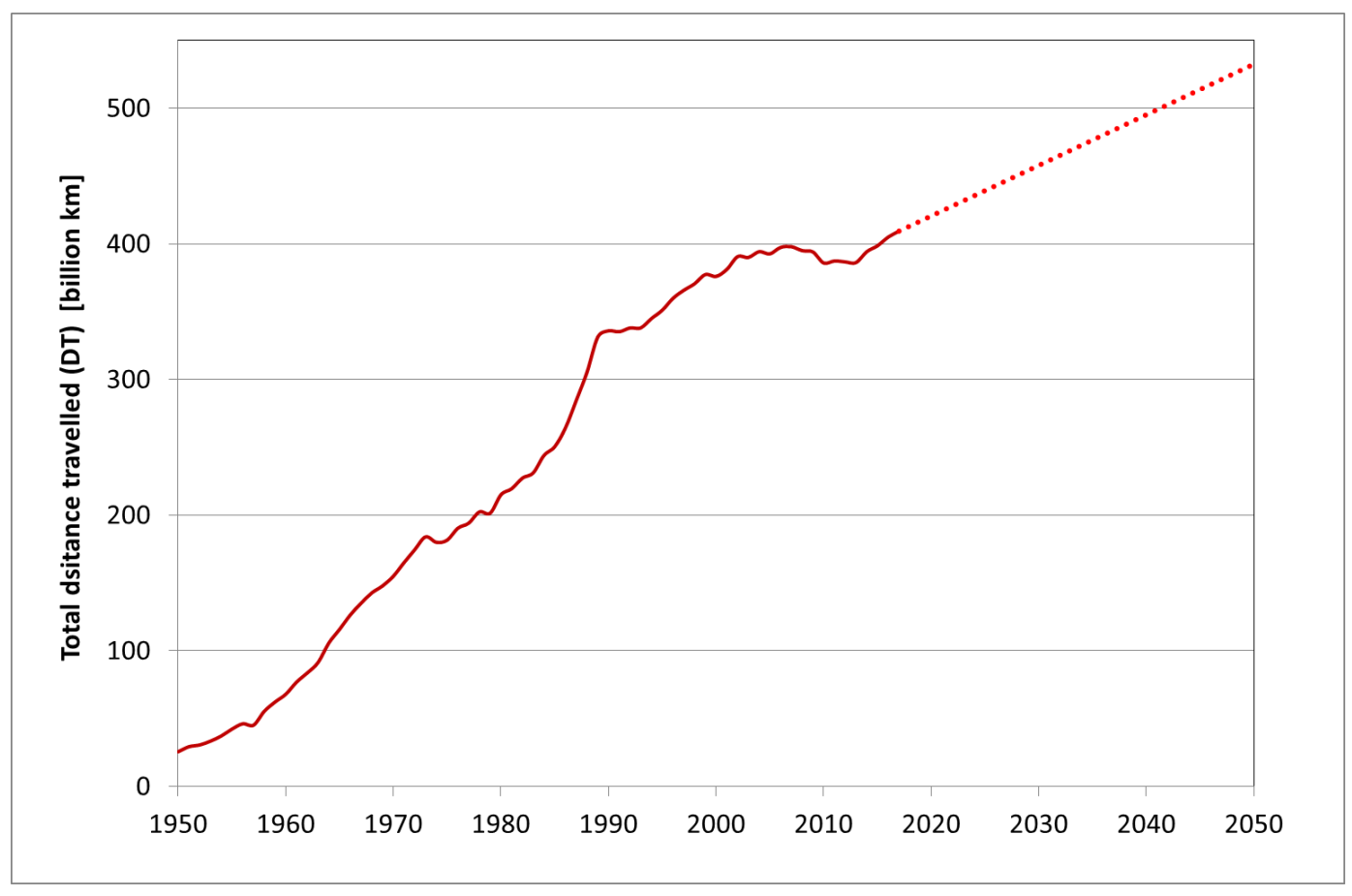

Figure 3. Total annual distance travelled (DT) by light duty vehicles on UK roads. Continuous line $=$ historical data (DfT, 2018b); dotted line = linear extrapolation to 2050 (DfT, 2018c, Scenario 1).

The numbers of private cars and taxis (including private hire vehicles) on UK roads in 2018 were 30 million and 280 thousand respectively (DfT, 2019), and for simplicity, the total DT by all cars on UK roads in 2018 is considered to be covered by private cars. This leads to the calculation of an average yearly mileage for private vehicles equal to $13,708 \mathrm{~km} /$ year, and hence to a 14-year vehicle lifespan for a lifetime mileage of $190,000 \mathrm{~km}$; this calculation is in good agreement with the average reported lifespan of vehicles in the UK (DfT, 2018a). For EVs, it is assumed that the batteries will reach their end of life (EoL) simultaneously with the vehicle after 14 years. Although this is currently longer than the average battery warranty of 8 years provided by EV automakers, it is still consistent with the actual life expectancy for LIBs, which is reported to range from 10 to 20 years (EDF, 2020; BXu et al., 2016).

Vehicles operating under shared mobility schemes (TaaS vehicles) are anticipated to have higher vehicles utilization rates as compared to private vehicles, which can lead to increased wear and tear, and hence a reduced lifetime. Due to the lack of data, the yearly mileage for TaaS is taken as the combination of ridesharing and car-sharing mileages reported in the literature, to represent a broad range of TaaS vehicles, i.e., $64,000 \mathrm{~km} /$ year, which, combined with a lifetime mileage of $190,000 \mathrm{~km}$, results in a lifetime of 3 years (Amatuni et al., 2019; OECD/ITF, 2017; Crabtree, 2019). The vehicle lifetimes are then used to predict the number of vehicles reaching their EoL each year. Furthermore, it is assumed that there will be no secondhand market for TaaS vehicles, as their batteries are very likely to be replaced, and the vehicle itself may have little residual market value. Even those TaaS vehicles that fall on the lower end of the yearly mileage scale, such as those used in car sharing schemes (Amatuni et al., 2019), may be considered to be treated like rental cars, which are typically replaced on average every 3 years (Cho \& Rust, 2008; Mont, 2004).

The vehicle fleet model also takes account of the vehicles that were already part of the fleet before the starting year of analysis (2018); the decommissioning of such initial vehicle fleet was modelled on the basis of available information on past vehicle registrations for up to 14 years in the past (i.e., from 2003); the 
decommissioning of the small number of additional vehicles that could not be accounted for on the basis of the registration data ( $2.5 \%$ of the total 2018 fleet) was then assumed to be spread over the course of the first 10 years of analysis (i.e., 2018-2028).

In the model, the balancing condition is then set that each year, the cumulative decommissioned service amount, i.e., the cumulative $\mathrm{km}$ no longer available because of old vehicles reaching their EoL, be exactly compensated for by new vehicle registrations (while considering that each private vehicle is expected to cover 13,708 km/year, and each TaaS vehicle $64,000 \mathrm{~km} /$ year). Specifically, the number of new private and Taas vehicles each year is further determined by a time-dependent parameter setting the ratio of TaaS to private new registrations, as discussed above when discussing the "baseline" vs. "TaaS" scenarios under alternative consideration. Even though in reality there may be a small further number of vehicle additions to the fleet which are not accounted for by such balancing condition (e.g., vehicles that are purchased as luxury goods and which end up being driven very little), this was deemed to be not significantly influential and was left out of the scope of the present model for the sake of clarity and simplicity.

By tracking the evolution of the number of new, in-service and EoL LDVs (subdivided into private ICEVs, private EVs and TaaS EVs) on UK roads with yearly resolution, the model is thus able to predict the associated cumulative demand for LIB materials in the LDV sector, and the annual outflow of EoL EV LIBs. EV battery size and mass varies with vehicle segment. EVs are currently still in an early stage of adoption, and therefore in the LDV fleet model the expected segment composition of the EV fleet as a whole is projected on the basis of the current (2017) ICEV segment composition for all registered vehicles, and since the latter has not changed significantly in recent years, it is then assumed to remain constant through to 2050 for both EV and ICEVs. Thus, the average LIB pack mass is calculated at around $323 \mathrm{~kg}$, equating to a usable storage capacity of approximately 50kWh, based on current LIB technology (this latter value is then expected to change in the future, as discussed in Section 2.2) (Electric Vehicle Database; Battery University; Raugei et al, 2018).

\begin{tabular}{|c|c|c|c|c|c|}
\hline $\begin{array}{l}\mathrm{EV} \text { and LIB } \\
\text { parameters }\end{array}$ & Description & Formula & $\begin{array}{l}\text { Starting }(\mathrm{t}=0) \\
\text { /default value }\end{array}$ & Units & Refs/notes/assumptions \\
\hline DT & $\begin{array}{c}\text { Total distance } \\
\text { travelled by all cars } \\
\text { on UK roads each } \\
\text { year }\end{array}$ & & $409,400,000,000$ & $\mathrm{~km} /$ years & (DfT, 2018a) \\
\hline$V_{-} 0$ & $\begin{array}{l}\text { Total number of } \\
\text { private cars on UK } \\
\text { roads in } 2017 \\
\text { (year 0) }\end{array}$ & & $29,865,900$ & & (DfT, 2018a) \\
\hline$M$ & $\begin{array}{l}\text { Vehicle lifetime } \\
\text { mileage }\end{array}$ & & 190,000 & $\mathrm{~km}$ & $\begin{array}{l}\text { LIB 1st lifetime (in EV) } \\
\text { assumed = M } \\
\text { (Ricardo AEA, 2015) }\end{array}$ \\
\hline$M V_{p}$ & $\begin{array}{l}\text { private vehicle } \\
\text { yearly mileage }\end{array}$ & $\frac{D T}{\mathrm{~V}_{-} 0}$ & 13,708 & $\mathrm{~km} /$ years & \\
\hline
\end{tabular}




\begin{tabular}{|c|c|c|c|c|c|}
\hline$T_{p}$ & $\begin{array}{l}\text { private vehicle } \\
\text { lifetime }\end{array}$ & $\frac{M}{M V_{p}}$ & 14 & years & \\
\hline$M V_{t}$ & $\begin{array}{l}\text { TaaS vehicle yearly } \\
\text { mileage }\end{array}$ & & 64,000 & $\mathrm{~km} /$ years & \\
\hline$T_{t}$ & $\begin{array}{l}\text { TaaS vehicle } \\
\text { lifetime }\end{array}$ & $\frac{M}{M V_{t}}$ & 3 & years & \\
\hline$V S C$ & EV LIB pack mass & & 323 & kg & $\begin{array}{l}\text { Based on current EV data } \\
\text { weighted by vehicle } \\
\text { segment (2017 UK } \\
\text { passenger vehicle } \\
\text { registration data) } \\
\text { (Battery University, 2020; } \\
\text { Raugei et al., 2018) }\end{array}$ \\
\hline$V E C$ & $\begin{array}{c}\text { EV electricity } \\
\text { consumption (use } \\
\text { phase) }\end{array}$ & & 0.2 & $\begin{array}{l}\mathrm{kWh}(\text { electr)/ } \\
\mathrm{km}\end{array}$ & $\begin{array}{c}\text { Based on EV data weighted } \\
\text { by vehicle segment } \\
\text { (Raugei et al., 2018) }\end{array}$ \\
\hline
\end{tabular}

Table 2. Basic EV and LIB parameters and assumptions.

\subsection{EV battery evolution}

The EV battery evolution model tracks the electrode composition of future generations of lithium-ion batteries, based on the expected battery technology advancement in the automotive sector. The battery composition allows determination of the amount of metals required per battery in each year. This information is then fed to the vehicle fleet model to quantify the annual demand for key battery metals required by the LDV sector.

A typical LIB cell is composed of a graphite anode, a metal oxide or phosphate cathode and a liquid electrolyte. The type of cathode formulation dictates the characteristics and the performance of the LIB, and therefore it plays a vital role in its improvement (Liu et al., 2016). The widely used cathode chemistries today by EV manufacturers are lithium iron phosphate (LFP), nickel cobalt aluminium oxide (NCA), and nickel manganese cobalt (NMC). LFP is mainly utilized by EV manufacturers in China and it its market share is expected to dwindle due to the improved driveability performance of NCA and NMC batteries (LFP batteries still retain potential for short-range vehicles, electric buses and electric bikes in the coming years) (Pelegov et al., 2018; Pillot, 2019; IEA, 2020). The majority of registered EVs in the UK and globally use either NCA or NMC cathode types. NMC is the most widely adopted battery chemistry by most EV manufacturers and its market share is expected to increase further in the coming decades, alongside improved driving ranges (IEA, 2020; Ding et al., 2019; Or et al., 2020). For this reason, in this study the entire vehicle fleet is assumed to use NMC batteries.

The improvement in the driving range of the vehicle depends on the energy density of the battery and this is dictated mostly by its cathode chemistry. The changes in cathode chemistries have direct implications on the demand of material. The original NMC-111 cathode composition had a significant share of cobalt which influenced the cost of the battery due to the metal's supply chain risk and price spikes in recent years, and it 
is currently being phased out (IEA, 2020; Azevedo et al, 2018). It is expected that in the near future NMC batteries will follow a trend towards higher nickel content, from the already common NMC-622 to future NMC-811, as this will increase the energy density of the cell and reduce the reliance on cobalt (Merriman, 2019; Element Energy, 2016; Ding et al., 2019). There is much current research on different battery technologies such as lithium-metal solid state and lithium-sulphur to provide improvements relative to LIBs in the future; however, these technologies exhibit large uncertainties in their working capability, and are not yet deemed viable for commercialisation (Zeng et al., 2019; Borah et al., 2020). Therefore, considering LIBs have already established themselves in the EV industry, it is assumed here that the NMC chemistry will continue to dominate in the EVs sector through to 2050.

The trends for the amounts of four key metals per kWh of battery pack (Olivetti et al., 2017), lithium (Li), nickel $(\mathrm{Ni})$, manganese $(\mathrm{Mn})$ and cobalt $(\mathrm{Co})$, are tracked in the model in order to quantify their corresponding overall demand. The model assumes a linear progression in the improvement in the battery energy density to 2035, due to a gradual hand-over from NMC-622 to NMC-811. After that, a further linear improvement in energy density is expected to take place thanks to a reduction in the weight of the battery pack casing and ancillary systems. It is further assumed that all energy density improvements will be exploited to achieve increased vehicle driving range, while the overall mass of the battery pack is considered to remain constant all the way to 2050. Table 3 summarizes the expected bi-modal trends in LIB energy density and key metal contents from 2020 to 2050.

\begin{tabular}{|c|c|c|c|c|c|c|}
\hline Year & Cathode type & $\begin{array}{c}\text { kWh(LIB) } \\
/ \mathrm{kg} \text { (LIB) }\end{array}$ & $\begin{array}{c}\mathrm{kg}(\mathrm{Li}) \\
/ \mathrm{kWh}(\mathrm{LIB})\end{array}$ & $\begin{array}{c}\mathrm{kg}(\mathrm{Ni}) \\
/ \mathrm{kWh}(\mathrm{LIB})\end{array}$ & $\begin{array}{c}\text { kg(Mn) } \\
/ \text { kWh(LIB) }\end{array}$ & $\begin{array}{c}\text { kg(Co) } \\
/ \text { kWh(LIB) }\end{array}$ \\
\hline 2020 & NMC-622 & 0.15 & 0.126 & 0.641 & 0.2 & 0.214 \\
\hline 2035 & NMC-811 & 0.25 & 0.111 & 0.75 & 0.088 & 0.094 \\
\hline 2050 & NMC-811 & 0.275 & 0.111 & 0.75 & 0.088 & 0.094 \\
\hline
\end{tabular}

Table 3. Summaries the basic parameters regarding the battery evolution adopted from (Element Energy, 2016; IEA, 2020; Olivetti et al., 2017).

\subsection{Grid battery storage}

The on-going move from a high-carbon to a low-carbon energy supply mix is going to entail a high penetration of intermittent renewables while at the same time satisfy an increased peak demand due to the electrification of transport (Zero, 2019); this undoubtedly creates a challenge to balance the power supply and demand. In the future, a reduced presence of conventional dispatchable power plants such as gas turbines is expected to not only make it difficult to provide the flexibility needed in the grid but also cause a reduction in the grid inertia, hence making the grid more susceptible to instability (Ulbig et al., 2014). Therefore, efforts to decarbonize the electricity sector must also focus on ensuring system stability and power delivery in a sustainable, affordable and reliable manner (Sanders et al., 2016). At the same time, in the future there will be very large numbers of EoL EV batteries, with potential to provide energy storage for the grid (Engel et al., 2019; Abdelbaky et al., 2020; Greim et al., 2020). National Grid's FES estimate the demand for energy storage technologies to meet the various decarbonisation targets. Specifically, in the FES "Leading the way" scenario, battery storage is expected to increase to $56.2 \mathrm{GWh}$ in 2050 (National Grid, 
2020), and this provides ample opportunity to reuse EoL EV batteries. This section examines the potential for second-life batteries to meet the demand for grid storage. The "Grid Battery Storage" model tracks the additional and residual required storage capacity that will be met by both second life and purpose-built LIBs stacks in each year, consistently with the overall yearly requirement for battery storage projected by FES "Leading the way" Scenario.

LIBs in EV applications undergo both power and capacity fade, the latter affecting more significantly the EV driveability performance (Saxena et al., 2015). The capacity fading of EV LIBs at the end of their first life is determined by the combination of cycle aging and calendar aging. Aging due to the number of times the battery is discharged and recharged is known as cycle aging, whereas calendar aging is the natural aging process of the battery, independent of charge and discharge cycles (Xu et al., 2016). Based on expected EV mileage, the trends of cycle aging and calendar aging were extrapolated here from De Gennaro et al. (2020), leading to estimations for the capacity fade at EoL equal to $20 \%$ of the initial usable capacity for TaaS EVs, and $30 \%$ for Private EVs; in the latter case, the most significant effect was found to be calendar aging (Redondo-Iglesias et al, 2018). Once EV batteries are retired from their first life, they can be reused to serve in less demanding applications in their second life, such as for stationary energy storage, which can eliminate some of the environmental and energy impacts associated with manufacturing new batteries (MartinezLaserna et al, 2018). Currently the largest second-life initiatives are: "Daimler Mobility House" with 13MWh of second-life batteries used for compensating power fluctuations (Daimler, 2015); "Advanced Battery Storage" launching this year with $60 \mathrm{MWh}$ of second-life batteries to facilitate the integration of renewables by 2020 (Groupe Renault, 2018); and the "SmartHubs Connected Energy" pilot project which is set to launch in 2021 with $14.4 \mathrm{MWh}$ of second-life batteries to provide grid balancing services (Connected Energy). As the UK grid transitions from distribution network operators (DNOs) to distribution system operators (DSOs), this could allow electric vehicles and small-scale batteries to participate in flexibility services to enhance the utilization of renewables and reducing the peak demand (PWC, 2019; Element-Energy, 2019). Although this can be a good opportunity to bring potential value to second life batteries and V2G, there are still technical and regulatory barriers which need to be overcome (Catapult, 2020; PWC, 2019).

Unlike EV batteries, stationary grid-level energy storage does not necessarily require the high energy density provided by NCA and NMC technologies. Therefore, the model assumes all purpose-built LIBs for grid energy storage are of LMO cathode composition. LMO is a mature technology without the presence of high supply risk metals, making it a safe choice for stationary storage. Energy storage batteries can participate in various grid applications such as reducing peak demand, smoothing the power output from renewable generation, controlling the ramp rate and maintaining the grid frequency (Hesse et al, 2017). The vast number of applications that LIBs can participate in makes determining their remaining lifespan quite uncertain. Based on the lifetime studies for purpose-built grid-level energy storage in various applications, a lifetime of 10 years is assumed for dedicated first-life LIBs (Thorbergsson et al, 2013; Zhang et al, 2019). For second life batteries, studies suggest that batteries retired from their first life after 8 to 10 years could be re-used for an additional 5 to over 10 years, depending on the type of battery applications they participate in (Hossain et al., 2019; Smith et al., 2017; Casals et al., 2019). Some studies have even assumed a 20 year total lifetime, in which second life is determined by subtracting the first life from the total lifetime (Greim et al., 2020; Hossain et al., 2019). In this paper, a conservative assumption of a 5-year lifespan is made for second-life grid applications. Table 4 summarizes the basic parameters and assumption made for second-life NMC LIBs, and grid-dedicated LMO LIBS. 
Furthermore, V2G is expected to come into play by year 2026, according to the projections of the FES "Leading the way" scenario, from 22GWh of storage capacity in 2030 to $270 \mathrm{GWh}$ in 2050 . V2G is a type of demand-response service which allows EVs to communicate with the electricity grid to either provide electricity to the grid or limit their charging rate to shift and reduce peak demand (Corp, 2017). According to the FES assumptions, a growing share of all EVs would end up participating in V2G services, up to $45 \%$ in 2050 (National Grid, 2020). When assuming such V2G storage capacities and engagement ratios in this dynamic material flow model, the additional average yearly load on each EV battery (relative to the drive cycle consumption) remains below $1 \%$. Therefore, it seems unlikely that V $2 \mathrm{G}$ would significantly impact the average expected LIB lifetimes in the EV fleet as a whole.

With regards to the three overall scenarios presented in Section 2, in scenario I "worst case") there is zero collection of EoL EV LIBs, and so the entire battery demand for grid storage is only met by purpose-built LIBs. In scenario II ("baseline") the collected EoL EV LIBs are from private EVs, whereas in scenario III ("TaaS") the collected EoL EV LIBs are from a mix of private and TaaS EVs. In both the latter scenarios the collection rate for EoL EV LiBs is increased linearly from a conservative $80 \%$ in 2020 to $99 \%$ in 2050. The initial estimate for year 2020 is based on the disclosed collection figures on EV batteries and EoL vehicles (European Commission, 2019). Although the disclosed figures are reported to be higher, they present significant missing data (European Commission, 2019).

The yearly available storage capacity of EoL EV LIBs is based on the collected amount of EoL LIBs tracked in the "Vehicle Fleet" model and the residual storage capacity of EoL EV LIBs in that particular year. The residual battery storage capacity at EoL depends on the cathode composition tracked by the "Battery Evolution" model and the capacity fade of the battery in its first life. For EoL private and TaaS EVs, the composition of the battery is based on the year the EV was introduced in the vehicle fleet, which is 14 years and 3 years before, respectively.

The "Grid Battery Energy Storage" model quantifies the total storage capacity met each year by second-life batteries and purpose-built LIBs up to 2050. The FES "Leading the way" scenario provides the expected installed battery storage capacity (kWh) through to 2050, and this is used to calculate the additional demand for storage capacity required each year. The latter is set to be preferentially met by second-life LIBs. When the available storage capacity of EoL EV LIBs is not sufficient, the residual demand is then met by purposebuilt LIBs in that particular year. As both the second-life and purpose-built LIBs reach the end of their remaining life and need replacement, the model then assumes that the additional storage capacity demand created by such replacement is again preferentially met by EoL EV LIBs.

\begin{tabular}{|c|c|c|c|}
\hline $\begin{array}{l}\text { Grid LIB and } 2^{\text {nd }} \text { life } \\
\text { Parameters }\end{array}$ & Default value & Units & Refs/notes/assumptions \\
\hline Energy Density of LMO LIB & 0.114 & $\mathrm{kWh} / \mathrm{kg}$ & (Notter et al., 2010) \\
\hline Li content in LMO LIB & 0.006 & $\begin{array}{c}\mathrm{kg}(\mathrm{Li}) / \mathrm{kg} \\
\text { (battery } \\
\text { pack) }\end{array}$ & $\begin{array}{l}\text { Based on Ecoinvent foreground } \\
\text { inventory data on LMO } \\
\text { production } \\
\text { (Ecoinvent, 2020; Notter et al., } \\
\text { 2010) }\end{array}$ \\
\hline
\end{tabular}




\begin{tabular}{|c|c|c|c|}
\hline Mn content in LMO LIB & 0.099 & $\begin{array}{l}\mathrm{kg}(\mathrm{Mn}) / \mathrm{kg} \\
\text { (battery } \\
\text { pack) }\end{array}$ & $\begin{array}{l}\text { Based on Ecoinvent foreground } \\
\text { inventory data on LMO } \\
\text { production } \\
\text { (Ecoinvent, 2020; Notter et al., } \\
\text { 2010) }\end{array}$ \\
\hline $\begin{array}{l}\text { Average 1st life lifetime for } \\
\text { LIBs used in grid-level } \\
\text { applications }\end{array}$ & 10 & years & $\begin{array}{l}\text { Assumption based on literature } \\
\text { studies (Thorbergsson et al, } \\
\text { 2013; Zhang et al, 2019) }\end{array}$ \\
\hline Average 2 nd life lifetime & 5 & years & $\begin{array}{l}\text { Assumption based on literature } \\
\text { studies } \\
\text { (Hossain et al., 2019; Smith et } \\
\text { al., 2017; Casals et al., 2019) }\end{array}$ \\
\hline $\begin{array}{l}\text { LIB capacity fade at EoL for } \\
\text { private EVs }\end{array}$ & $30 \%$ & & $\begin{array}{l}\text { Extrapolated based on } \\
\text { (De Gennaro et al., 2020) }\end{array}$ \\
\hline $\begin{array}{c}\text { LIB capacity fade at EoL for } \\
\text { TaaS EVs }\end{array}$ & $20 \%$ & & $\begin{array}{l}\text { Extrapolated based on } \\
\text { (De Gennaro et al., 2020) }\end{array}$ \\
\hline
\end{tabular}

Table 4. Basic second-life and purpose-built LIB parameters and assumptions.

\subsection{Battery recycling}

The battery recycling model tracks the retired EV batteries from the vehicle fleet entering recycling after their first and second lives. It also keeps track of the amounts of battery metals ( $\mathrm{Li}, \mathrm{Ni}, \mathrm{Mn}$ and $\mathrm{Co}$ ) respectively required by the vehicle fleet and available after recycling each year. The collection of EoL purpose-built grid batteries has not been considered because there may not be enough incentive for it. It is then assumed in the model that once the battery metals are recovered in a particular year, they are sent straight back to the manufacturing of EV batteries to meet the demand for EVs in the same year, as calculated in the vehicle fleet model.

The most mature and, historically, the most widely employed process for recycling spent LIBs is the pyrometallurgical recycling process. However, it is characterised by high energy requirement, relatively low metal recovery rates and adverse environmental impacts (Arambarri et al., 2019) which can reduce the environmental benefits of EVs. Therefore, considering the higher efficiency of metal recovery that is typical of hydrometallurgical recycling processes, and the fact that a number of large-scale implementations of this technology are already under way in Asia, the model assumes that in the future all EV batteries entering recycling will undergo hydrometallurgical treatment (Zheng et al., 2018; Wang et al., 2015; Gaines, 2018; American Manganese Inc., 2020). Table 5 summaries the expected recovery efficiencies for the four considered metals using hydrometallurgical recycling (Greim et al., 2020; Cheret \& Santen, 2007; Chen \& Zhou, 2014; Melin, 2019).

\begin{tabular}{|ccc|}
\hline Metals & Recovery Efficiency & Reference \\
\hline $\mathrm{Li}$ & $95 \%$ & (Greim et al., 2020) \\
\hline
\end{tabular}




\begin{tabular}{|ccc|}
\hline $\mathrm{Ni}$ & $99 \%$ & (Cheret \& Santen, 2007) \\
\hline $\mathrm{Mn}$ & $95 \%$ & $\begin{array}{c}\text { (Chen \& Zhou, 2014; Melin, } \\
\text { 2019) }\end{array}$ \\
\hline Co & $94 \%$ & (Cheret \& Santen, 2007) \\
\hline
\end{tabular}

Table 5. Recovery efficiencies of metals in hydrometallurgical recycling process.

\section{Results and Discussion}

Figure 4 illustrates the modelled development of the total UK LDV fleet, from 2020 to 2050, respectively when assuming: (A) no penetration of TaaS ("worst case" and "baseline" scenarios), and (B) a relatively rapid success of various TaaS schemes, eventually cumulatively accounting for up to $45 \%$ of all new LDV registrations in 2050 ( "TaaS" scenario). In all scenarios the entire UK fleet is expected to be essentially rid of conventional ICEVs by the early years of the 2040 decade. While this might appear as a rather extreme outcome over a relatively short time scale, it is in fact entirely consistent with the current government plans to mandate the complete phase out of all new ICEVs by 2030, combined with an average lifetime of 14 years for private LDVs, as discussed in Section 2.1. The reduction in demand for total vehicle units in the "TaaS" scenario $(-13 \%$ by 2050$)$ is the direct result of the improved efficiency with which TaaS vehicles can deliver the same unit of service (in terms of km travelled per year) when compared to privately-owned vehicles.

Figure 5 then illustrates a direct overlay of the expected new vehicle registrations in each year, under the "worst case" and "baseline" vs. "TaaS" scenarios assumptions.

Figure 6 presents the different quantities of EoL EV LIBs that are collected and either sent directly to recycling or repurposed for second-life grid storage. In the "worst case" scenarios, no collection is assumed to take place, and as a result all of the EoL EV batteries are "lost". In the "baseline" scenario, EoL LIB material flows begin in the year 2032, when the first private EVs reach their EoL. Virtually all collected LIBs go to second life in the first year, due to the demand for grid storage initially almost absorbing all available EoL LIBs; however, the share of EoL EV LIBs that are sent straight to recycling then quickly increases, due to the much more rapid growth in EV numbers vs. grid storage requirements, and it eventually reaches almost $90 \%$ in 2050. In the "TaaS" scenario, the shorter-lived TaaS EVs can already be seen reaching their EoL as early as in 2024, but until 2029, the majority of the collected EoL LIBs go straight to recycling, since the demand for grid storage is still small. Then, after 2032, the arrival of larger numbers of EoL private EVs leads to a similar trend as in the "baseline" scenario, in terms of a preponderance of direct recycling over second-life. Thus, as a whole, over the three decades under consideration, from 2020 to 2050, the impact of second-life applications on LIB recycling rates can be expected to be minimal.

Figure 7 then presents the results of the grid battery storage model, where the blue line indicates the expected incremental demand for installed LIB storage capacity relative to the previous year (this information is provided in National Grid's "Leading the way" FES projections (National Grid, 2020), and applies equally to all three scenarios), and the three green lines indicate the results of three model calculations for the resulting net demand for purpose-built stationary (LMO) LIBs, respectively in the "worst case", "baseline" and "TaaS" scenarios, after accounting for: (i) the need to replace LIB units when they reach their expected end of service life, and (ii) the availability of additional storage capacity provided by 
second-life EV LIBs. The results clearly differ for the three scenarios under consideration. In the "worst case" scenario the yearly demand for purpose-built LIB storage for the grid rises to over $5 \mathrm{GWh}$ by the early 2030s and then essentially fluctuates between 5 and $7 \mathrm{GWh} /$ year, due to the need to keep replacing the batteries that reach their EoL. In the "baseline" scenario, instead, the availability of second-life LIBs from the LDV sector significantly curbs the demand for purpose-built LIB storage after 2030, bringing it down to zero by 2032. In other words, after 2032 the availability of EoL EV LIBs is expected to exceed the total demand for LIB storage capacity by the grid, even when considering the limited lifespan of both the originally installed LMO batteries and the second-life NMC batteries coming from EoL EVs, and the multiple replacements required.

The "TaaS" scenario then further improves on these results, because the more rapid turn-over of TaaS vehicles in the LDV fleet effectively brings forward the availability of a sufficient quantity of EoL EV LIBs to be re-used in second-life applications. In this third scenario, therefore, the demand for purpose-built LMO batteries for grid storage is essentially brought down to zero as soon as in 2024.

Finally, Figure 8 presents the results of the complete material flow analysis of the net demand for virgin LIB metals ( $\mathrm{Li}, \mathrm{Mn}, \mathrm{Co}$ and $\mathrm{Ni}$ ) in the $\mathrm{UK}$, when considering the link between the transport and energy sectors resulting from the second-life reuse of EoL EV LIBs, and the effect of LIB recycling. The individual demands for $L i$ and $M n$ by the LDV fleet and the electricity grid are also reported separately (respectively, using dashed lines and dotted lines). A second vertical scale is used to plot the demand for $\mathrm{Ni}$, since the latter is generally one order of magnitude larger than those for the other metals.

Comparing the results for the "baseline" and "worst case" scenarios puts in stark relief the key roles that recycling and, to a lesser extent, second life are poised to play in reducing the demand for virgin LIB metals. Specifically, in the "worst case" scenario the demands for all metals first peak in the early 2030s, respectively at around 25,000 tonnes/year ( $\mathrm{Li}, \mathrm{Co}$ and $\mathrm{Mn}$ ) and approximately 160,000 tonnes/year ( $\mathrm{Ni}$ ), then dip by 20$30 \%$ by 2040 , before rising even higher towards 2050 (the dynamics of these demand curves are primarily dictated by the sigmoid growth of the EV fleet - cf. Figure 5).

Instead, in the "baseline" scenario a steadily growing collection rate for EoL EV LIBs, from $80 \%$ in 2020 to $99 \%$ in 2050 , is enough to not only prevent a second peak in demand for all key LIB metals, but to effectively drive the need to source them from raw resources back down to present levels by 2050, thereby almost "closing the loop" on the LIB sector and dramatically staving off all concerns related to any long-term shortage of supply.

The "TaaS" scenario then produced even more remarkable results, in that the projected contraction in the total LDV fleet size, combined with the more rapid turn-over of EoL LIBs afforded by the widespread deployment of TaaS vehicles, were found to drive the net demand for virgin LIB metals to negative values after 2040. In other words, if the conditions for this scenario were met, there would be a net surplus of Li, $\mathrm{Mn}$, Co and Ni availability coming from the combined throughput of LIBs in the LDV and electricity grid sectors in the UK in the last decade of the considered time frame, from 2040 to 2050. 

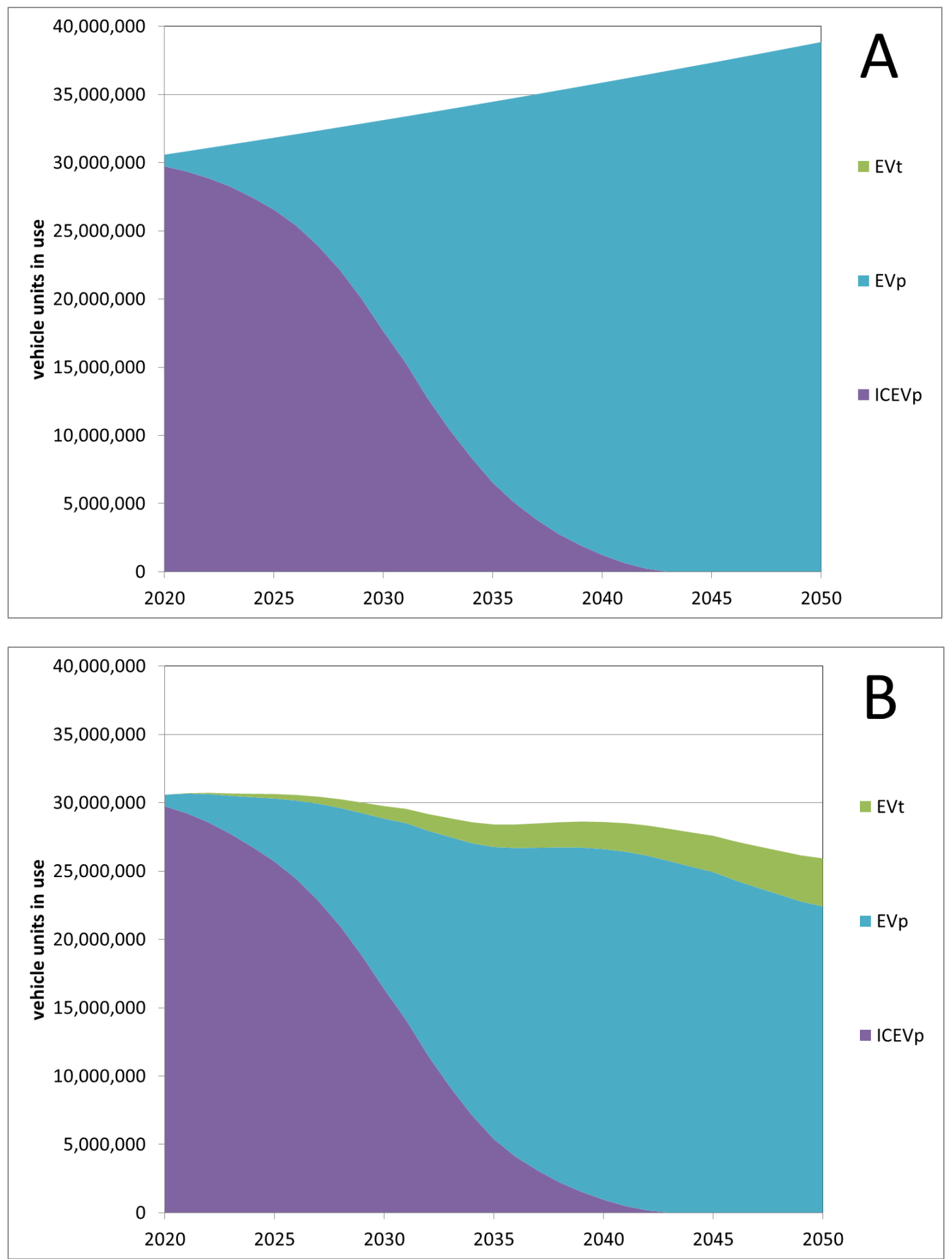

Figure 4. Projections for the total light duty vehicle fleet in the UK. $A=$ "worst case" and "baseline" scenarios; $B$ = "TaaS" scenario. EVt = electric vehicles used for transport-as-a-service; $E V p=$ privately owned electric vehicles; ICEVp = privately owned internal combustion engine vehicles. 


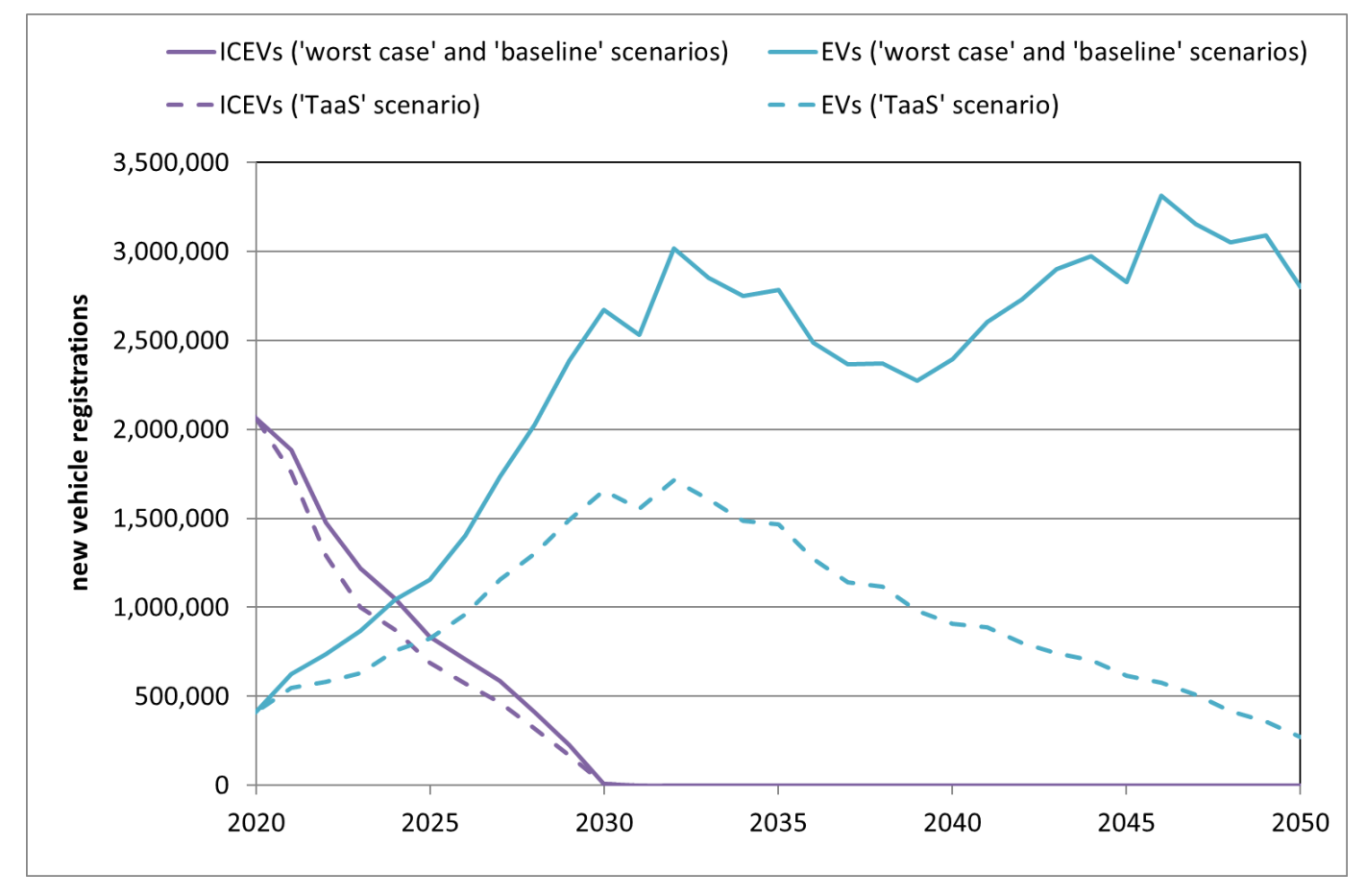

Figure 5. Projections of new vehicle registrations per year, "worst case" and "baseline" vs. "TaaS" scenarios.

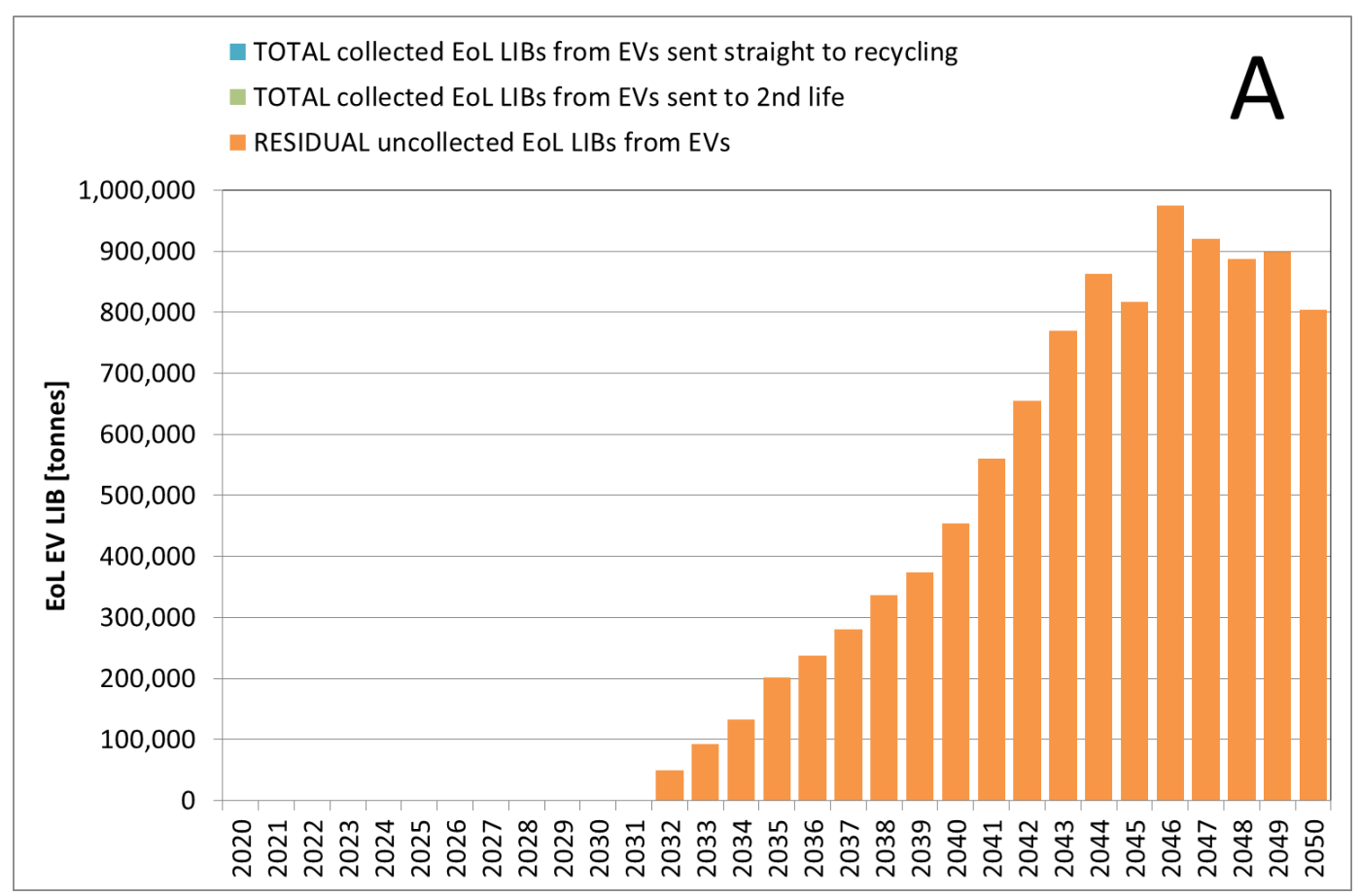




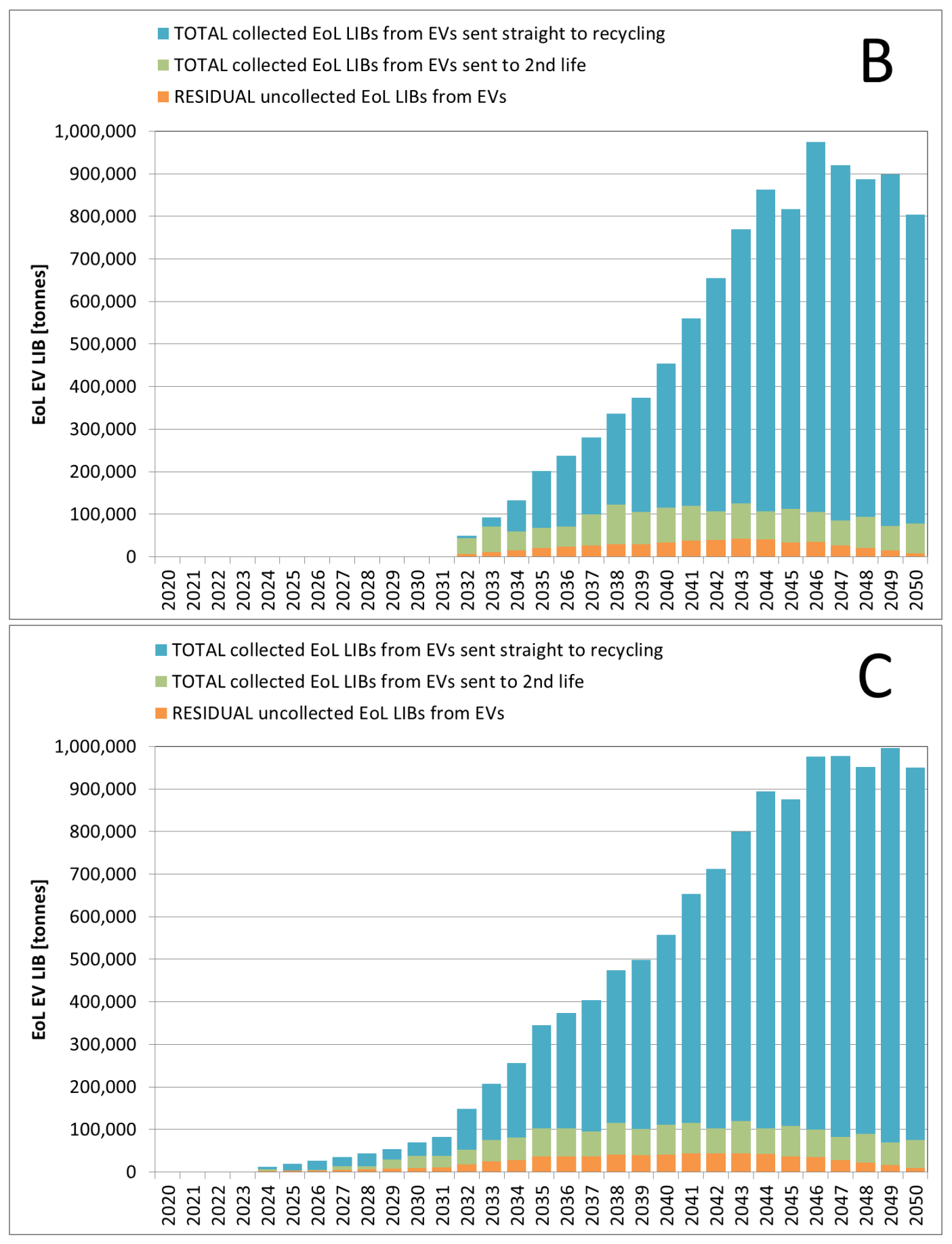

Figure 6. Quantities of EoL EV LIBs that are respectively: (i) uncollected; (ii) collected and sent straight to recycling; and (iii) collected and repurposed for second-life grid storage applications. $A=$ "worst case" scenario; B = "baseline" scenario; C = "TaaS" scenario. 


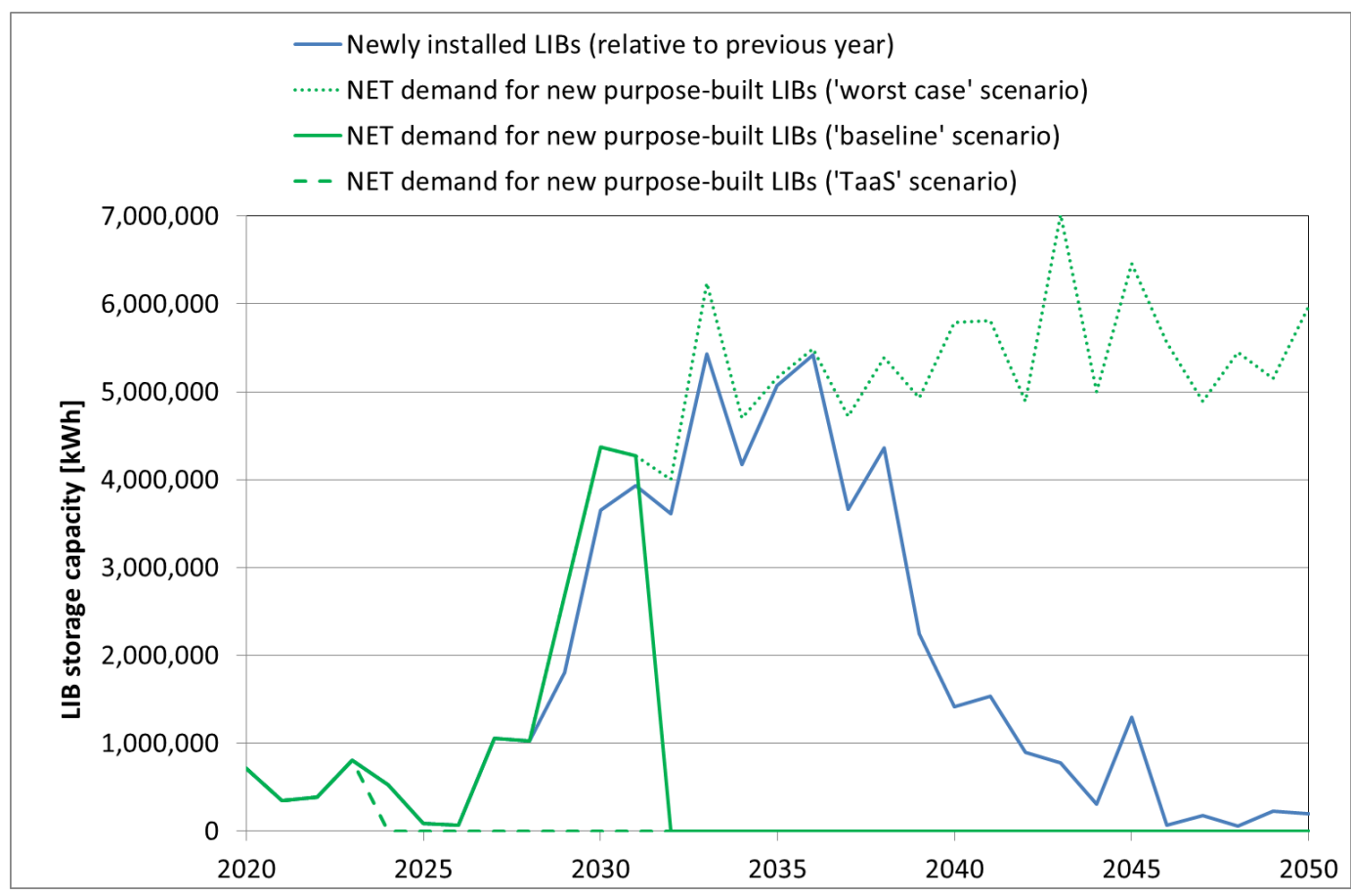

Figure 7. Projections of demand for purpose-built LIB storage capacity for the UK electricity grid.

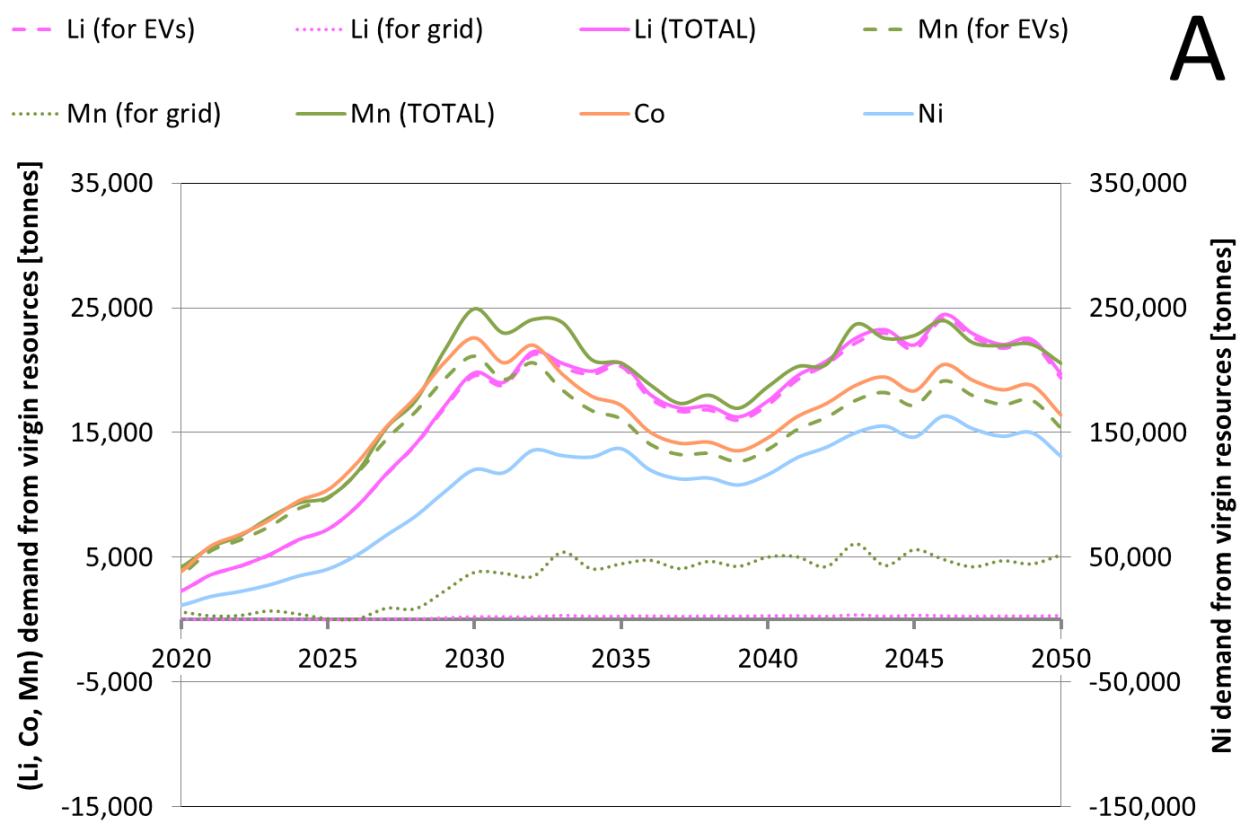



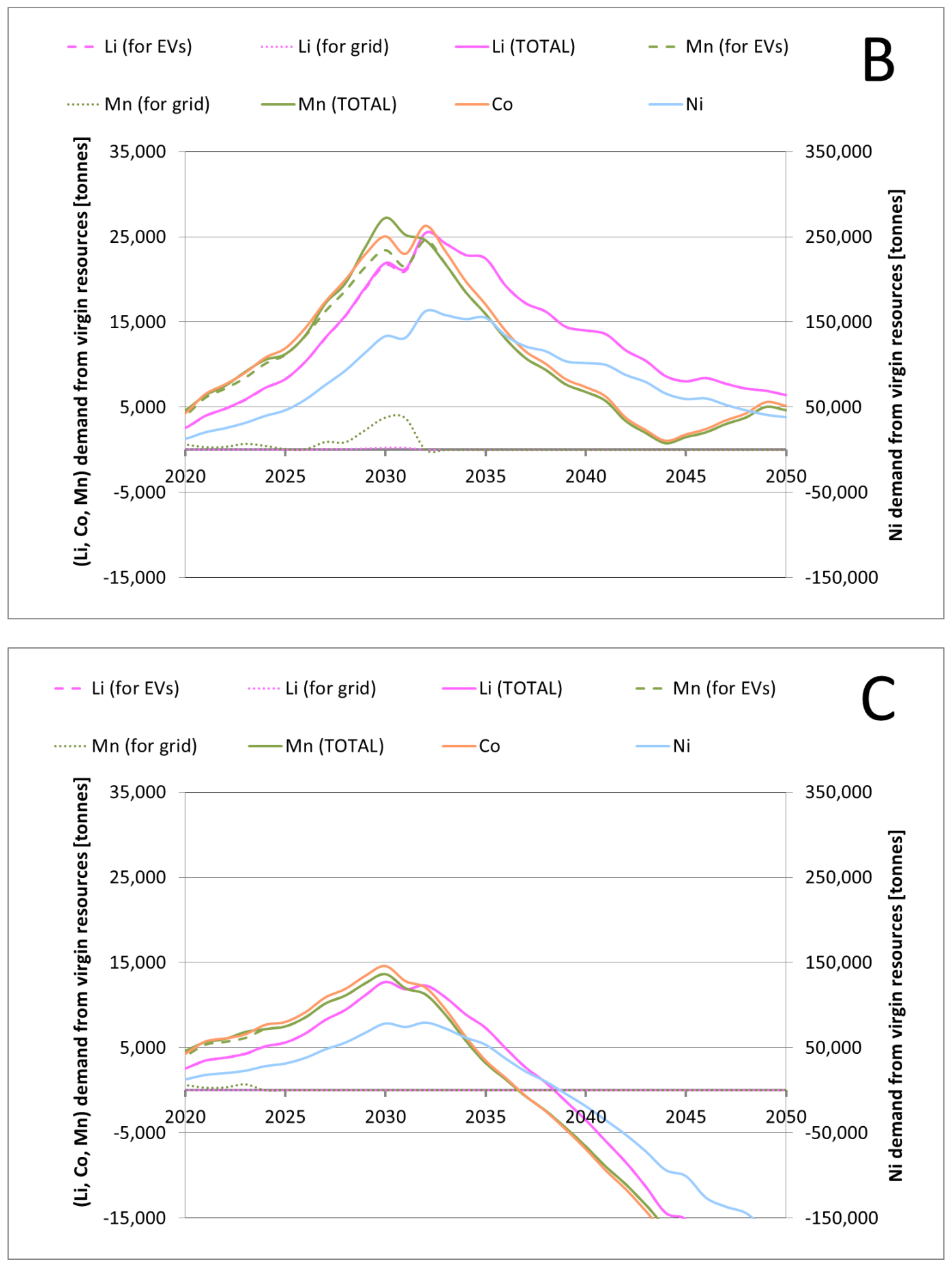

Figure 8. Projections of total demand for virgin LIB metals in the UK. $\mathrm{A}=$ "worst case" scenario; $\mathrm{B}=$ "baseline" scenario; $\mathrm{C}=$ "TaaS" scenario. Note separate vertical scale for $\mathrm{Ni}$ demand. 


\section{Conclusions}

The collection and recycling of end-of-life electric vehicle battery packs is not only critical in pursuing resource circularity in the supply chain for lithium-ion batteries, but also very effective in achieving such a goal within the next three decades in the UK. This has been proven beyond doubt by this integrated and internally consistent dynamic material flow analysis of the ever-more-tightly-coupled light duty vehicle and electricity sectors.

It has also been shown that repurposing EoL EV batteries for grid storage applications is clearly a recommendable strategy, in that it allows dramatically curbing the requirement for purpose-built battery storage deployment, while only marginally affecting the demand for virgin materials for the EV sector. This is due to a combination of: (i) the order-of-magnitude larger expected throughput of battery storage capacity in the transport vs. the electricity sectors, and (ii) the relatively short time lag imposed by second life on the eventual recovery of the battery metals by recycling.

Finally, it is clear that a projected large shift in behaviour change, from the conventional vehicle ownership model to a shared mobility model with a focus on transport as a service, could further reduce the demand for virgin battery metals, to the point where the UK could actually become a net supplier of $\mathrm{Li}, \mathrm{Co}, \mathrm{Mn}$ and $\mathrm{Ni}$ to the battery industry by 2040. An oversupply of recycled battery metals could have spill-over benefits in terms of facilitating the penetration of LIBs into other sectors too, including heavy-duty vehicles. Of course, such oversupply cannot be expected to last indefinitely, and supply and demand are bound to eventually balance out again in the farther future, when the penetration of TaaS reaches a plateau and the overall lightduty vehicle fleet size stabilizes again. However, attempting to draft quantitative scenarios that extend significantly beyond three decades is fraught with increasingly large uncertainties, not only about vehicle use trends, but also about other potential energy storage technologies that might become commercially viable and partly displace LIBs as the preferred option. Further degrees of uncertainty are also tied to potential future exports of recycled LIB metals and to the possible mass penetration of LIBs into other markets beyond the transport sector; however, these considerations fall outside of the scope of this paper and do not detract from the general validity of the results presented here, in terms of the effectiveness of recycling and shared mobility.

\section{Acknowledgements}

The financial support for this work provided by the Faraday Institution under project 'ReLIB' [grant number FIR005] is gratefully acknowledged. The authors also wish to thank the two anonymous reviewers for providing though-provoking comments and suggestions that led to improved clarity and transparency in the manuscript.

\section{References}

Abdelbaky, M., Peeters, J. R., Duflou, J. R., Dewulf, W. (2020). Forecasting the EU recycling potential for batteries from electric vehicles. Procedia CIRP, 90, 432-436. https://doi.org/10.1016/j.procir.2020.01.109 
Abdel-Monem, M., Hegazy, O., Omar, N., Trad, K., Van den Bossche, P., Van Mierlo, J. (2017) Lithium-ion batteries: Comprehensive technical analysis of second-life batteries for smart grid applications. 2017 19th European Conference on Power Electronics and Applications (EPE'17 ECCE Europe), Warsaw, 2017, pp. 1-16. https://doi.org/10.23919/EPE17ECCEEurope.2017.809938

Alves Dias, P., Blagoeva, D., Pavel, C., Arvanitidis, N. (2018). Cobalt: demand-supply balances in the transition to electric mobility. European Commission JRC Science for Policy report.

http://publications.jrc.ec.europa.eu/repository/bitstream/JRC112285/jrc112285_cobalt.pdf

Amatuni, L., Ottelin, J., Steubing, B., Mogollon, J. (2019). Does car sharing reduce greenhouse gas emissions? Life cycle assessment of the modal shift and lifetime shift rebound effects. arXiv preprint arXiv:1910.11570.

Ambrose, J. (2020). UK plans to bring forward ban on fossil fuel vehicles to 2030. Retrieved October 26, 2020, from https://www.theguardian.com/environment/2020/sep/21/uk-plans-to-bring-forward-ban-onfossil-fuel-vehicles-to-2030

American Manganese Inc. (2020). Achieves 92\% Extraction of Lithium-ion Battery Material with Continuous Operation of Pilot Plant Project. Retrieved October 26, 2020, from

https://americanmanganeseinc.com/american-manganese-inc-achieves-92-extraction-of-lithium-ionbattery-material-with-continuous-operation-of-pilot-plant-project/

Arambarri, J., Hayden, J., Elkurdy, M., Meyers, B., Abu Hamatteh, Z. S., Abbassi, B., Omar, W. (2019). Lithium ion car batteries: Present analysis and future predictions. Environmental Engineering Research, 24(4), 699710. DOI: https://doi.org/10.4491/eer.2018.383

Arbib, J., Seba T., (2017). RethinkX, Rethinking Transportation 2020-2030. Retrieved October 26, 2020, from https://static1.squarespace.com/static/585c3439be65942f022bbf9b/t/59f279b3652deaab9520fba6/150906 3126843/RethinkX+Report_102517.pdf

Azevedo, M., Campagnol, N., Hagenbruch, T., Hoffman, K., Lala, A., Ramsbottom, O. (2018). Lithium and Cobalt - A Tale of Two Commodities. Mckinsey \& Company. Retrieved October 26, 2020, from https://www.mckinsey.com/ /media/mckinsey/industries/metals\%20and\%20mining/our\%20insights/lithiu m\%20and\%20cobalt\%20a\%20tale\%20of\%20two\%20commodities/lithium-and-cobalt-a-tale-of-twocommodities.ashx

Baars, J., Domenech, T., Bleischwitz, R., Melin, H. E., Heidrich, O. (2020). Circular economy strategies for electric vehicle batteries reduce reliance on raw materials. Nature Sustainability, 1-9.

https://doi.org/10.1038/s41893-020-00607-0

Bálint, S., Ziemann, S., Weil, M. (2015). Potential metal requirement of active materials in lithium-ion battery cells of electric vehicles and its impact on reserves: Focus on Europe. Resources, Conservation and Recycling, 104(A), 300-310, https://doi.org/10.1016/j.resconrec.2015.07.011

Battery University (2020). BU-1003: Electric Vehicle (EV). Retrieved October 26, 2020, from https://batteryuniversity.com/learn/article/electric_vehicle_ev

Borah, R., Hughson, F. R., Johnston, J., Nann, T. (2020). On battery materials and methods. Materials Today Advances, 6, 100046. https://doi.org/10.1016/j.mtadv.2019.100046 
British Geological Survey (BGS) (2020). Critical raw meterials. https://www.bgs.ac.uk/geologyprojects/critical-raw-materials/

Casals, L. C., García, B. A., Canal, C. (2019). Second life batteries lifespan: Rest of useful life and environmental analysis. Journal of environmental management, 232, 354-363.

https://doi.org/10.1016/j.jenvman.2018.11.046

Catapult (2020) Storage flexibility net zero series second life batteries. Retrieved October 26, 2020, from https://es.catapult.org.uk/reports/storage-and-flexibility-second-life-batteries/

Chen, X., Zhou, T. (2014). Hydrometallurgical process for the recovery of metal values from spent lithium-ion batteries in citric acid media. Waste Management \& Research, 32(11), 1083-1093.

https://doi.org/10.1177/0734242X14557380

Cheret, D. and S. Santen (2007). Battery recycling. In United States Patent, (11/108,321). USA: Scanara Plasma Technology AB Umicore.

Cho, S., Rust, J. (2008). Is econometrics useful for private policy making? A case study of replacement policy at an auto rental company. Journal of econometrics, 145(1-2), 243-257.

https://doi.org/10.1016/j.jeconom.2008.05.015

Choubey, P.K., Chung, K.-S., Kim, M.-S., Lee, J.-C., Srivastava, R.R. (2017) Advance review on the exploitation of the prominent energy-storage element Lithium. Part II: From sea water and spent lithium ion batteries (LIBs). Minerals Engineering, 110, 104-121, https://doi.org/10.1016/j.mineng.2017.04.008

Choubey, P.K., Kim, M.-S., Srivastava, R.R., Lee, J.-C., Lee, J.-Y. (2016) Advance review on the exploitation of the prominent energy-storage element: Lithium. Part I: From mineral and brine resources. Minerals Engineering, 89, 119-137, https://doi.org/10.1016/j.mineng.2016.01.010

CoMoUK. Co-mobility Themes. Retrieved October 26, 2020, from https://como.org.uk/shared-mobility/comobility-themes/mobilityhubs/

Connected Energy. SmartHubs: Smart Local Energy System. Retrieved October 26, 2020, from https://www.c-e-int.com/smarthubs/

Corp, N. (2017). GTM: Can Nuvve Make V2G Work in the Real World? - NUVVE Corp. NUVVE Corp. Retrieved 25 October 2020, from https://nuvve.com/gtm-can-nuvve-make-v2g-work-in-the-real-world/.

Crabtree, G. (2019) BATTERY TECHNOLOGY: The coming electric vehicle transformation. Retrieved October 26, 2020, from https://science.sciencemag.org/content/sci/366/6464/422.full.pdf

Daimler (2015). E-mobility thought to the end: World's largest 2nd-use battery storage unit set to connect to the grid. Retrieved from: https://media.daimler.com/marsMediaSite/ko/en/9920193

De Gennaro, M., Paffumi, E., Martini, G., Giallonardo, A., Pedroso, S., Loiselle-Lapointe, A. (2020). A case study to predict the capacity fade of the battery of electrified vehicles in real-world use conditions. Case Studies on Transport Policy, 8(2), 517-534. https://doi.org/10.1016/j.cstp.2019.11.005

Department for Transport (DfT) (2018a). The Road to Zero: Next steps towards cleaner road transport and delivering our Industrial Strategy, Retrieved October 26, 2020, from 
https://assets.publishing.service.gov.uk/government/uploads/system/uploads/attachment_data/file/73946 0/road-to-zero.pdf

Department for Transport (DfT) (2018b). Road traffic (vehicle kilometres) by vehicle type in Great Britain. Retrieved October 26, 2020, from https://www.gov.uk/government/statistical-data-sets/road-trafficstatistics-tra

Department for Transport (DfT) (2018c). Road traffic forecasts 2018. Retrieved November 27, 2020, from https://www.gov.uk/government/publications/road-traffic-forecasts-2018

Department for Transport (DfT) (2019). Taxis, private hire vehicles and their drivers (TAXI). Retrieved October 26, 2020, from https://www.gov.uk/government/statistical-data-sets/taxi01-taxis-private-hirevehilces-and-their-drivers

Department for Transport (DfT) (2020). Road traffic statistics. Retrieved October 26, 2020, from https://roadtraffic.dft.gov.uk/about\#: :text=Annual\%20Average\%20Daily\%20Flow\%20(AADF,the\%20corresp onding\%20length\%20of\%20road).

Dewulf, J., Van der Vorst, G., Denturck, K., Van Langenhove, H., Ghyoot, W., Tytgat, J., Vandeputte, K. (2010) Recycling rechargeable lithium ion batteries: Critical analysis of natural resource savings. Resources, Conservation and Recycling, 54( 4), 229-234, https://doi.org/10.1016/j.resconrec.2009.08.004

Ding, Y., Cano, Z. P., Yu, A., Lu, J., Chen, Z. (2019). Automotive Li-ion batteries: current status and future perspectives. Electrochemical Energy Reviews, 2(1), 1-28. doi:10.1007/s41918-018-0022-z.

E-Car Club (n.d.) Hourly electric vehicles for hire. Retrieved October 26, 2020, from https://ecarclub.co.uk/vehicles/

Ecoinvent (2020). Life Cycle Inventory Database. http://www.ecoinvent.org

EDF (2020). All about electric car batteries. Retrieved October 26, 2020, from https://www.edfenergy.com/electric-cars/batteries

Electric Vehicle Database. Retrieved October 26, 2020, from https://ev-database.uk/

Element Energy (2016). Battery Cost and Performance and Battery Management System

Element Energy (2019). V2GB - Vehicle to Grid Britain: Requirements for market scale-up (WP4). Retrieved October 25, 2020, from http://www.element-energy.co.uk/wordpress/wpcontent/uploads/2019/06/V2GB_WP-4-report-Requirements-for-market-scale-up.pdf

Engel, H., Hertzke, P., Siccardo, G. (2019). Second-life EV batteries: The newest value pool in energy storage. McKinsey Center for Future Mobility, Global Editorial Services. Retrieved October 26, 2020, from https://www.mckinsey.com/industries/automotive-and-assembly/our-insights/second-life-ev-batteries-thenewest-value-pool-in-energy-storage

European Comission (2019). Commission staff working document on the evaluation of the Directive 2006/66/EC on batteries and accumulators and waste batteries and accumulators and repealing Directive 91/157/EEC. Retrieved October 26, 2020, from https://www.eurobat.org/images/news/positionpapers/final_acea_jama_kama_ila_eurobat_position_paper.pdf 
Faria, R., Marques, P., Moura, P., Freire, F., Delgado, J., de Almeida, A.T. (2013). Impact of the electricity mix and use profile in the life-cycle assessment of electric vehicles. Ren Sust Energy Rev 24:271-287, http://dx.doi.org/10.1016/j.rser.2013.03.063

Foresight. (2019). A time of unprecedented change in the transport system. Retrieved October 26, 2020, from

https://assets.publishing.service.gov.uk/government/uploads/system/uploads/attachment_data/file/78086 8/future_of_mobility_final.pdf

Gaines, L. (2018). Lithium-ion battery recycling processes: Research towards a sustainable course. Sustainable materials and technologies, 17, e00068. DOI: 10.1016/j.susmat.2018.e00068

Greim, P., Solomon, A.A., Breyer, C. (2020). Assessment of lithium criticality in the global energy transition and addressing policy gaps in transportation. Nature Communications, 11, 4570.

https://doi.org/10.1038/s41467-020-18402-y

Grosjean, C., Herrera Miranda, P., Perrin, M., Poggi, P. (2012) Assessment of world lithium resources and consequences of their geographic distribution on the expected development of the electric vehicle industry. Renewable and Sustainable Energy Reviews, 16(3), 1735-1744, https://doi.org/10.1016/j.rser.2011.11.023

Groupe Renault. (2018). Groupe Renault is launching "Advanced Battery Storage", the biggest stationary energy storage system from electric vehicle (ev) batteries in europe. Retrieved October 25, 2020, from https://en.media.groupe.renault.com/assets/groupe-renault-is-launching-advanced-battery-storage-thebiggest-stationary-energy-storage-system-from-electric-vehicle-ev-batteries-in-europe-21216357-

989c5.html?lang=en

Hein, R., Kleindorfer, P.R., Spinler, S. (2012) Valuation of electric vehicle batteries in vehicle-to-grid and battery-to-grid systems. Technological Forecasting and Social Change, 79(9), 1654-1671, https://doi.org/10.1016/j.techfore.2012.06.002

Hesse, H. C., Schimpe, M., Kucevic, D., Jossen, A. (2017). Lithium-ion battery storage for the grid-A review of stationary battery storage system design tailored for applications in modern power grids. Energies, 10(12), 2107. https://doi.org/10.3390/en10122107

Hoekstra A. (2019). The Underestimated Potential of Battery Electric Vehicles to Reduce Emissions. Joule, 3, 1404-1414. https://doi.org/10.1016/j.joule.2019.06.002

Hossain, E., Murtaugh, D., Mody, J., Faruque, H. M. R., Sunny, M. S. H., Mohammad, N. (2019). A comprehensive review on second-life batteries: current state, manufacturing considerations, applications, impacts, barriers \& potential solutions, business strategies, and policies. IEEE Access, 7, 73215-73252. https://ieeexplore.ieee.org/stamp/stamp.jsp?tp=\&arnumber=8718282

IEA (2020). Global EV Outlook: Entering the Decade of Electric Drive. Retrieved October 26, 2020, from https://www.iea.org/reports/global-ev-outlook-2020

Kubitz, B. (2020), Future Transport on trial. Retrieved October 26, 2020, https://smarttransportpub.blob.core.windows.net/web/1/root/insight-future-mobility-zones-beate-kubitzlow-res-pdf.pdf 
Lindley, D. (2010). Smart grids: The energy storage problem. Nature, 463, 18-20.

https://doi.org/10.1038/463018a

Liu, C., Neale, Z. G., Cao, G. (2016). Understanding electrochemical potentials of cathode materials in rechargeable batteries. Materials Today, 19(2), 109-123. https://doi.org/10.1016/j.mattod.2015.10.009

MaaS Alliance. (n.d.). Https://maas-alliance.eu/homepage/what-is-maas/. Retrieved October 26, 2020, from https://maas-alliance.eu/homepage/what-is-maas/

Martinez-Laserna, E., Gandiaga, I., Sarasketa-Zabala, E., Badeda, J., Stroe, D. I., Swierczynski, M., Goikoetxea, A. (2018). Battery second life: Hype, hope or reality? A critical review of the state of the art. Renewable and Sustainable Energy Reviews, 93, 701-718. https://doi.org/10.1016/j.rser.2018.04.035

Mayyas A., Steward D., Mann M. (2019). The case for recycling: Overview and challenges in the material supply chain for automotive li-ion batteries. Sustainable Materials and Technolgies, 19, e00087. https://doi.org/10.1016/j.susmat.2018.e00087

Melin, H. E. (2019). State-of-the-art in Reuse and Recycling of Lithium-ion Batteries-A Research Review. Swedish Energy Agency, Stockholm. Retrieved October 26, 2020, from https://www.energimyndigheten.se/globalassets/forskning--innovation/overgripande/state-of-the-art-inreuse-and-recycling-of-lithium-ion-batteries-2019.pdf

Merriman, D. (2019). Roskill: The EV Revolution: Impacts on critical raw material supply chains. Retrieved October 26, 2020, from https://www.minersoc.org/wp-content/uploads/2019/05/3ICM-Merriman.pdf

Möller, T., Padhi, A., Pinner, D., Tschiesner, A. (2019). The future of mobility is at our doorstep. McKinsey Center for Future Mobility. Retrieved October 26, 2020, from

https://www.mckinsey.com/ /media/McKinsey/Industries/Automotive\%20and\%20Assembly/Our\%20Insight s/The\%20future\%20of\%20mobility\%20is\%20at\%20our\%20doorstep/The-future-of-mobility-is-at-ourdoorstep.pdf

Mont, O. (2004). Institutionalisation of sustainable consumption patterns based on shared use. Ecological economics, 50(1-2), 135-153. https://doi.org/10.1016/j.ecolecon.2004.03.030

Narins, T.P. (2017). The battery business: Lithium availability and the growth of the global electric car industry. The Extractive Industries and Society, 4( 2), 321-328. https://doi.org/10.1016/j.exis.2017.01.013

National Grid (2020). Future Energy Scenarios. https://www.nationalgrideso.com/future-energy/futureenergy-scenarios

Notter, D.A., Gauch, M., Widmer, R., Wager, P., Stamp, A., Zah, R., Althaus, H.-J. (2010). Contribution of LiIon Batteries to the Environmental Impact of Electric Vehicles. Environmental Science and Technology, 44(17), 6550

OECD/ITF (2017). Transition to Shared Mobility. https://www.itf-oecd.org/sites/default/files/docs/transitionshared-mobility.pdf 
Or, T., Gourley, S. W., Kaliyappan, K., Yu, A., Chen, Z. (2020). Recycling of mixed cathode lithium-ion batteries for electric vehicles: Current status and future outlook. Carbon Energy, 2(1), 6-43.

https://doi.org/10.1002/cey2.29

Ozdemir A., Murat Koc I., Sumer B. (2020). Comparative study on Well-to-Wheels emissions between fully electric and conventional automobiles in Istanbul. Transportation Research Part D: Transport and Environment, 87, 102508. https://doi.org/10.1016/j.trd.2020.102508

Pelegov, D. V., Pontes, J. (2018). Main drivers of battery industry changes: electric vehicles-a market overview. Batteries, 4(4), 65. https://doi.org/10.3390/batteries4040065

Petrauskienè K., Skvarnavičiūtè M., Dvarionienè J. (2020). Comparative environmental life cycle assessment of electric and conventional vehicles in Lithuania. Journal of Cleaner Production, 246, 119042.

https://doi.org/10.1016/j.jclepro.2019.119042

Pillot, C. (2019). Avicenne Energy: The Rechargeable Battery Market and Main Trends 2018-2030. Retrieved October 26, 2020, from http://cdn.ceo.ca.s3.amazonaws.com/1em2t4r-02\%20-

\%20Presentation\%20Avicenne\%20-\%20Christophe\%20Pillot\%20-\%2028\%20Mai\%202019.pdf

PricewaterhouseCoopers (PWC) (2019). Regulatory barriers for Smart Charging of EVs and second life use of EV batteries. Group Renault. Retrieved October 25, 2020, from https://group.renault.com/wpcontent/uploads/2020/05/deliverable-2_190517-elaad-final-report-regulatory-barriers-smart-chargingstc.pdf.

Rajaeifar, M.A., Heidrich, O., Ghadimi, P., Raugei, M., Wu, Y. (2020). Sustainable supply and value chains of electric vehicle batteries. Resources, Conservation \& Recycling, 161, 104905.

https://doi.org/10.1016/j.resconrec.2020.104905

Raugei, M., Hutchinson, A., Morrey, D. (2018). Can Electric Vehicles significantly reduce our dependence on non-renewable energy? Scenarios of compact vehicles in the UK as a case in point. Journal of Cleaner Production, 201: 1043-1051. https://doi.org/10.1016/j.jclepro.2018.08.107

Raugei, M., Kamran, M., Hutchinson, A. (2020). A prospective net energy and environmental life-cycle assessment of the UK electricity grid. Energies, 13(9):2207. https://doi.org/10.3390/en13092207

Redondo-Iglesias, E., Venet, P., Pelissier, S. (2018). Calendar and cycling ageing combination of batteries in electric vehicles. Microelectronics Reliability, 88, 1212-1215. https://doi.org/10.1016/j.microrel.2018.06.113

Ricardo-AEA (2015). Improvements to the definition of lifetime mileage of light duty vehicles Retrieved October 26, 2020, https://ec.europa.eu/clima/sites/clima/files/transport/vehicles/docs/ldv_mileage_improvement_en.pdf

Ritchie, H., Roser, M. (2020). $\mathrm{CO}_{2}$ and Greenhouse Gas Emissions. Our World in Data.

https://ourworldindata.org/co2-and-other-greenhouse-gas-emissions\#global-warming-to-date

Sanders, D., et al. (2016). An analysis of electricity system flexibility for Great Britain. Carbon Trust/Imperial College: London, UK. Retrieved October 26, 2020, from

https://assets.publishing.service.gov.uk/government/uploads/system/uploads/attachment_data/file/56898 2/An_analysis_of_electricity_flexibility_for_Great_Britain.pdf 
Saxena, S., Le Floch, C., MacDonald, J., Moura, S. (2015). Quantifying EV battery end-of-life through analysis of travel needs with vehicle powertrain models. Journal of Power Sources, 282, 265-276.

https://doi.org/10.1016/j.jpowsour.2015.01.072

Smith, K., Saxon, A., Keyser, M., Lundstrom, B., Cao, Z., Roc, A. (2017, May). Life prediction model for gridconnected Li-ion battery energy storage system. In 2017 American Control Conference (ACC) (pp. $4062-$ 4068). IEEE. https://www.nrel.gov/docs/fy17osti/67102.pdf

Sovacool, B.K., Hirsh, R.F. (2009) Beyond batteries: An examination of the benefits and barriers to plug-in hybrid electric vehicles (PHEVs) and a vehicle-to-grid (V2G) transition. Energy Policy, 37(3), 1095-1103, https://doi.org/10.1016/j.enpol.2008.10.005

Speirs, J., Contestabile, M., Houari, Y., Gross, R. (2014) The future of lithium availability for electric vehicle batteries. Renewable and Sustainable Energy Reviews, 35, 183-193,

https://doi.org/10.1016/j.rser.2014.04.018

The Guardian (2020). UK plans to bring forward ban on fossil fuel vehicles to 2030.

https://www.theguardian.com/environment/2020/sep/21/uk-plans-to-bring-forward-ban-on-fossil-fuelvehicles-to-2030

Thorbergsson, E., Knap, V., Swierczynski, M. J., Stroe, D. I., Teodorescu, R. (2013). Primary Frequency Regulation with Li-Ion Battery Energy Storage System - Evaluation and Comparison of Different Control Strategies. In Proceedings of the 35th International Telecommunications Energy Conference 'Smart Power and Efficiency', INTELEC 2013 (pp. 178). IEEE Press.

http://ieeexplore.ieee.org/xpls/abs_all.jsp?arnumber=6663276

UK government (2020). Final UK greenhouse gas emissions national statistics: 1990 to 2018.

https://www.gov.uk/government/statistics/final-uk-greenhouse-gas-emissions-national-statistics-1990-to2018

Ulbig, A., Borsche, T. S., Andersson, G. (2014). Impact of low rotational inertia on power system stability and operation. IFAC Proceedings, 47(3), 7290-7297. https://doi.org/10.3182/20140824-6-ZA-1003.02615

United States Geological Survey (USGS) (2020a). Lithium Statistics and Information.

https://www.usgs.gov/centers/nmic/lithium-statistics-and-information

United States Geological Survey (USGS) (2020b). Cobalt Statistics and Information.

https://www.usgs.gov/centers/nmic/lithium-statistics-and-information

US Department of Energy (US DoE) (2011). Critical materials strategy.

https://www.energy.gov/sites/prod/files/DOE_CMS2011_FINAL_Full.pdf

Wang, H., Friedrich, B. (2015). Development of a highly efficient hydrometallurgical recycling process for automotive Li-Ion batteries. Journal of Sustainable Metallurgy, 1(2), 168-178.

https://doi.org/10.1007/s40831-015-0016-6

World Resources Institute (WRI) (2020). World Greenhouse Gas Emissions: 2016.

https://www.wri.org/resources/data-visualizations/world-greenhouse-gas-emissions-2016 
Xu, B., Oudalov, A., Ulbig, A., Andersson, G., Kirschen, D. S. (2016). Modeling of lithium-ion battery degradation for cell life assessment. IEEE Transactions on Smart Grid, 9(2), 1131-1140.

https://doi.org/10.1109/TSG.2016.2578950

Zeng, X., Li, M., Abd El-Hady, D., Alshitari, W., Al-Bogami, A. S., Lu, J., mine, K. (2019). Commercialization of lithium battery technologies for electric vehicles. Advanced Energy Materials, 9(27), 1900161.

https://doi.org/10.1002/aenm.201900161

Zero, C. N. (2019). The UK's contribution to stopping global warming. Committee on Climate Change: London, UK. Retrieved October 26, 2020, from https://www.theccc.org.uk/publication/net-zero-the-ukscontribution-to-stopping-global-warming/

Zhang, Y., Xu, Y., Yang, H., Dong, Z. Y., Zhang, R. (2019). Optimal whole-life-cycle planning of battery energy storage for multi-functional services in power systems. IEEE Transactions on Sustainable Energy.

https://ieeexplore.ieee.org/document/8844110

Zheng, X., Zhu, Z., Lin, X., Zhang, Y., He, Y., Cao, H., Sun, Z. (2018). A mini-review on metal recycling from spent lithium ion batteries. Engineering, 4(3), 361-370. https://doi.org/10.1016/j.eng.2018.05.018

Ziemann, S., Mueller, D.B., Schebek, L., Weil, M. (2018). Modeling the potential impact of lithium recycling from EV batteries on lithium demand: A dynamic MFA approach. Resources, Conservation and Recycling, 133, 76-85. https://doi.org/10.1016/j.resconrec.2018.01.031 